\title{
A Study of Innovative Alkali-Activated Binders for Soil Stabilisation in the Context of Engineering Sustainability and Circular Economy
}

\author{
M. Mavroulidou ${ }^{1}$ (D) $\cdot$ C. Gray ${ }^{2} \cdot$ M. J. Gunn ${ }^{1} \cdot$ L. Pantoja-Muñoz $^{3}$
}

Received: 28 February 2021 / Accepted: 24 August 2021 /Published online: 9 September 2021

(C) The Author(s) 2021

\begin{abstract}
In the context of sustainability in the civil engineering industry, chemical ground improvement is becoming increasingly used, as a generally more sustainable alternative to replacing and landfilling unsuitable for construction ground. However, traditional soil stabilisers such as Portland cement or lime are not environmentally impact-free; international research effort is thus focusing on the development of innovative cementing agents. This paper presents results from a feasibility study on the development of suitable alkaliactivated slag cements for the stabilisation of two soils. A number of alkali-activators were considered, comprising potassium hydroxide, a range of alkali salts, as well as a material retrieved from waste (Paper Sludge Ash, PSA) which contains free lime. Indicative results of an extensive parametric study in terms of unconfined compressive strength (UCS) are shown, followed by results of ongoing oedometer tests to determine soil compressibility and some preliminary tests on selected soil/binder mixes to observe the durability to wetting-drying cycles. Overall, all alkali-activated cement mixes increased the UCS and stiffness of the soil. Carbonates and $\mathrm{Na}_{2} \mathrm{SiO}_{3}$ used on their own gave lower strength increases. The highest strengths were achieved from AAC with $\mathrm{KOH}$ and $\mathrm{Ca}(\mathrm{OH})_{2}$ from PSA, which showed similar strength gain. The latter material has shown consistently a lot of promise in terms of strength, stiffness and volumetric stability of the soil as well as treatment durability. Ongoing research focuses on further mix optimisation and a comprehensive mechanical and durability property testing supported by material analysis (mineralogical, chemical and microstructural) to gain a better understanding of the complex mechanisms involved.
\end{abstract}

Keywords Alkali-activated cements; · Soil stabilisation; · Paper sludge ash; · Ground granulated blast furnace slag

M. Mavroulidou

mavroum@1sbu.ac.uk

Extended author information available on the last page of the article 


\section{Introduction}

Professionals who develop or maintain civil infrastructure face major challenges when encountering inferior geomaterials (natural or man-made soils and rocks, including soil-like waste such as mine tailings, sludges, dredged sediments). To mitigate hazards due to inadequate engineering properties, such materials are usually removed and landfilled, generating a solid waste management problem; they are then replaced by more suitable for construction, non-renewable natural aggregate, transported to the site. With increased focus on improving construction sustainability, it is critically important to find ways of improving geomaterials rather than replacing them. Common geomaterial improvement techniques include the use of cementitious materials such as Ordinary Portland cement (OPC) or lime. Although this is a step towards more sustainable construction practices, the production of both OPC and lime at temperatures over $1200-1400^{\circ} \mathrm{C}$ is energy-intensive, and generates large amounts of greenhouse gases (e.g. $0.95 \mathrm{t}$ carbon dioxide per ton of OPC, i.e. ca. 5$7 \%$ of global anthropogenic $\mathrm{CO}_{2}$ emissions) and other air-polluting chemicals (e.g. sulphur dioxide, carbon monoxide, and nitric oxide). It also consumes non-renewable natural resources (e.g. 1.5t limestone and clay per ton of OPC) [1]. Alternative cementing materials are therefore actively sought, towards low-carbon, sustainable engineering solutions, contributing to the achievement of UN sustainable development goals (see e.g. [2]); the potential of using waste materials in the alternative cementitious binder composition is also targeted, to address solid waste management and transform waste to an opportunity, while reducing energy consumption, $\mathrm{CO}_{2}$ emissions and raw material use. In this context, alkali-activated cements (AAC) are emerging as promising candidates to replace traditional cements and are expected to be a key component of a sustainable future global construction materials industry [3]. Recent studies on AAC for concrete calculated up and to 55$75 \%$ overall $\mathrm{CO}_{2}$ reductions in alkali-activated ground granulated blast-furnace slag cement from the cradle to pre-construction, based on a number of performance efficiency indicators, binder and $\mathrm{CO}_{2}$ intensities [4]. Concerning AAC for soils, the carbon footprint of AAC geopolymer with fly ash activated by $\mathrm{NaOH}$ and $\mathrm{Na}_{2} \mathrm{SiO}_{3}$ used to stabilize a marine clay was calculated to be approximately $22 \%, 23 \%$ and $43 \%$ lower than that of common cement for strengths of $400 \mathrm{kPa}, 600 \mathrm{kPa}$ and $800 \mathrm{kPa}$ respectively [5].

AAC are binder systems produced by the reaction of an alkali metal source (solid or dissolved) with a solid (alumino-) silicate powder [6]. Alkali sources can be found in various soluble substances that can supply alkali metal ions (hydroxides, carbonates, sulphates, aluminates or oxides) to raise the $\mathrm{pH}$ of the mixture thus accelerating the dissolution of the solid precursor. The latter can be a natural or man-made pozzolan (e.g. volcanic ash, calcined clays etc.) or a by-product/waste material coming typically from various industrial or mining processes (e.g. metallurgical slags, fly ash, red mud, tungsten mine waste amongst other), construction and demolition waste (e.g. waste concrete, bricks, tiles, ceramics or glass), municipal waste (e.g. municipal waste ashes, recycled glass), agricultural waste (e.g. rice husk ash, palm oil fuel ash etc.) [3,6-16]; thus AAC are ideally suited as an outlet route for waste materials used as precursors but also as alkaline activators [17-19], and can support the development of a circular economy. Although this diversity of materials requires a case-bycase study, it also means that AAC are very versatile and locally adaptable, thus potentially minimising the transport of materials, which is a key factor for the development of sustainable future construction materials worldwide [3,20]. The wide variety of possible precursor materials is thus one of the major advantages of AAC.

AAC have gained worldwide attention relatively recently, predominantly as cements for concrete; conversely, the possibility of stabilising the soil with AAC systems similar to those used for 
concrete has been little researched. Examples of research papers using AAC for soils include works by Cristelo et al. [21-23], activating low-calcium and high-calcium fly ash, and Sargent [24], who stabilised soft alluvium soil using $\mathrm{NaOH}$-activated GGBS for high-speed rail application. Zhang et al. [25] used metakaolin-based geopolymer (usually classified as a type of AAC) for shallow soil mixing, and Du et al [1] stabilised a clay soil using lightweight geopolymer. Coudert et al [26] and Vitale et al [27, 28] performed a thorough material analysis to study the physico-chemical reaction evolution in soils treated with different $\mathrm{Na}_{2} \mathrm{SiO}_{3}$-activated fly ashes; the latter authors also assessed the one-dimensional compression behaviour of the treated soil samples for different binder contents and curing times. This was related to the chemo-physical evolution of the binders over curing time using X-Ray Diffraction (XRD) analysis. Syed et al. [29] used $\mathrm{NaOH}$ and $\mathrm{Na}_{2} \mathrm{SiO}_{3}$ - activated Class F fly ash to treat an expansive soil (black cotton soil) and assessed the success of the treatments in terms of California Bearing Capacity Ratio (CBR) and Unconfined Compressive Strength (UCS) increase. Pourakbar et al [16] activated locally available palm oil fuel ash as precursor using $\mathrm{NaOH}$ and $\mathrm{KOH}$, and successfully used it for the treatment of a clayey soil in terms of increase in UCS and ultimate bearing capacity.

This paper presents results of an ongoing feasibility study aiming to identify viable AAC systems for ground improvement. Filling in some of the gaps in previously presented work $[30,31]$ new AAC systems are introduced, containing new possible mix components (carbonates) as well as previously studied ingredients in different proportions. The focus is mix components that can be cheap $\left(\mathrm{Na}_{2} \mathrm{CO}_{3}\right)$ or potentially be sourced from waste streams to enhance further the sustainability of AAC. Thus, the AAC systems studied use as a precursor Ground Granulated Blast Furnace Slag (GGBS), an industrial by-product (of steel production) and include different alkali activators, amongst which $\mathrm{KOH}$ and $\mathrm{K}_{2} \mathrm{CO}_{3}\left(\mathrm{~K}_{2} \mathrm{CO}_{3}\right.$ and from this, $\mathrm{KOH}$, can be retrieved from the incineration of plant/food waste), $\mathrm{Na}_{2} \mathrm{SiO}_{3}$, which can be obtained from waste glass [17] or rice husk ash [18], and one waste material, Paper Sludge Ash (PSA), used as a source of CaO. PSA is the ash produced from the incineration of non-hazardous paper sludge, which is the main waste stream of the paper recycling industry. Steadily increasing amounts of PSA arising in the UK are predominantly landfilled, hence the interest in finding alternative outlets for this material.

The objectives of the collected experimental evidence are to a) identify most promising systems and exclude unsuccessful systems from future study; b) identify key factors affecting the performance of the AAC system, in order to design further experiments and optimize the most promising systems in the future. The success of the stabilisers is assessed in terms of the following criteria: a) increase in unconfined compressive strength (UCS), based on an extensive ongoing parametric study; b) reduction in the compressibility of the soil based on oedometer data; c) reduction in the propensity of an expansive soil to swell upon moisture content increase, based on free swelling oedometer test data. Some interim findings of interest on the durability to wetting-drying cycles of some of the treated soil mixes are also included but firm statements would require detailed physico-chemical analysis of the different systems, which is beyond the scope of this paper.

\section{Materials and Methods}

\section{Materials}

The soils used in this study were (a) an industrially supplied silt; (b) an expansive soil, i.e. a mixture of $70 \%$ kaolin clay from the South West of England and 30\% sodium activated 
bentonite. The precursor used in the AA binder mixes was GGBS from Hanson Regen. Activating blast furnace slag with a $\mathrm{CaO}-\mathrm{SiO}_{2}>70 \%$ (as in this study) gives a C-(A)-S-H (calcium (alumino-) silicate hydrate) gel as a main reaction product; this gel is similar to that obtained during OPC hydration but the Ca:Si ratio was reported to be below 1.5, whereas the $\mathrm{Ca}$ :Si ratio of OPC is ca. 2.0. [32]. To be suitable for alkali activation, slags need to: a) have a vitreous content of $\geq 90 \%$; b) have a large specific surface of $400-600 \mathrm{~m}^{2} / \mathrm{kg}$; c) be preferably $\mathrm{pH}$-basic [33]. All these requirements were satisfied as according to information provided by the suppliers, the GGBS had a vitreous content of $98 \%$, a specific surface of $450-550 \mathrm{~m}^{2} / \mathrm{kg}$ and $\mathrm{pH}>10$ and an adequate (moderate) modulus of activity or quality coefficient $\mathrm{K}_{\mathrm{q}}=1.65$ (defined as $\mathrm{K}_{\mathrm{q}}=\left(\mathrm{CaO}+\mathrm{MgO}+\mathrm{Al}_{2} \mathrm{O}_{3}\right) /\left(\mathrm{SiO}_{2}+\mathrm{MnO}\right)$ [34]). This is of importance as the higher the modulus of activity or quality coefficient is, the higher the amount of alkaline compounds present in the slag, giving better hydraulic properties.

The analytical grade alkali activators used were sodium silicate $\mathrm{Na}_{2} \mathrm{SiO}_{3}$ solution of a modulus $\mathrm{M}=\mathrm{SiO}_{2} / \mathrm{NaO}_{2}=2$; potassium hydroxide $\mathrm{KOH}$ pellets ( $\geq 99 \%$ purity); anhydrous potassium carbonate pellets ( $\geq 99 \%$ purity) and anhydrous sodium carbonate pellets $(\geq 99 \%$ purity) (supplied by Fisher Scientific). Paper Sludge Ash (PSA) was from a newspaper recycling company in the South-East of England. PSA is mainly a calcium aluminosilicate, as the principal compounds are lime $(\mathrm{CaO})(\mathrm{ca} 60 \%)$, silica $\left(\mathrm{SiO}_{2}\right)$ and alumina $\left(\mathrm{Al}_{2} \mathrm{O}_{3}\right)$; the total combined content of $\mathrm{SiO}_{2}$ and $\mathrm{Al}_{2} \mathrm{O}_{3}$ and $\mathrm{Fe}_{2} \mathrm{O}_{3}$ is typically less than $50 \%$; hence, the material is not a pozzolan [34]. It is cementitious and due to its high free $\mathrm{CaO}$ content it has a $\mathrm{pH}=12.3-12.4$ [35].

Typical chemical compositions of GGBS and PSA according to the suppliers are shown in Table 1; the two materials have similarities in composition; however attempts to activate PSA in its as-rceived form to produce cement for structural concrete were not successful [36] consistently with Bernal et al. [37], who, for the same PSA, did not observe the formation of geopolymer under the activation conditions they used. Therefore, the PSA was considered mostly as an alkaline activator of the GGBS in the system, with the free $\mathrm{CaO}$ hydrating to $\mathrm{Ca}(\mathrm{OH})_{2}$ in the presence of water.

The PSA was used as received (it was not milled); its particle size distribution (accroding to [38]) compared to that of the GGBS is shown in Fig. 1. It can be seen that the PSA is coarser than the GGBS, with an average particle size $\left(\mathrm{d}_{50}\right)$ of ca. $90 \mu \mathrm{m}$. It is also coarser than the average particle size $d_{50}$ of the tested soils, i.e. $4.5 \mu \mathrm{m}$ and $20 \mu \mathrm{m}$ for kaolin and silt respectively (based on hydrometer testing, BSI 1990 [39]); bentonite is even finer, consisting of $92 \%$ montmorillonite clay with only $5 \%$ of the particles $>150 \mu \mathrm{m}$ (based on supplier's data).

\section{Mix Design}

The aim of the mix design was to perform a study on the effect of the following parameters that are known to affect the performance of AAC (see, e.g. [40]): (a) the type of alkaline activator, i.e. $\mathrm{KOH}, \mathrm{Ca}(\mathrm{OH})_{2}$ from the hydration of $\mathrm{CaO}$ contained in the PSA and different alkali salts used on their own or in mixes with other activators (i.e. $\mathrm{KOH}$ and PSA); (b) the dosage of the activator per dry mass of soil; (c) the ratio of activator solution mass/GGBS mass per dry mass of soil; (d) the solution molarity (increased molarity would lead to a better rate of dissolution; however, if molarity is too high the dissolution decreases (see, e.g. [41]). To decouple the possible effect on soil strength gain due to GGBS, which is a latent cementitious material, specimens treated with GGBS only were also prepared. 
Table 1 Typical oxide composition (reported as oxide wt.\%) of PSA and GGBS

\begin{tabular}{lll}
\hline Chemical composition & PSA & GGBS \\
\hline $\mathrm{SiO}_{2}$ & 19.2 & 34.68 \\
$\mathrm{Al}_{2} \mathrm{O}_{3}$ & 8.7 & 14.16 \\
$\mathrm{CaO}$ & 60.7 & 38.74 \\
$\mathrm{MgO}$ & 2.8 & 7.74 \\
$\mathrm{Fe}_{2} \mathrm{O}_{3}$ & 0.5 & 0.05 \\
$\mathrm{Na}_{2} \mathrm{O}$ & 0.15 & 0.46 \\
$\mathrm{~K}_{2} \mathrm{O}$ & 0.2 & 0.55 \\
$\mathrm{SO}_{3}$ & 0.48 & 0.21 \\
$\mathrm{P}_{2} \mathrm{O}_{5}$ & 0.17 & \\
$\mathrm{TiO}_{2}$ & 0.2 & \\
$\mathrm{SrO}$ & 0.09 & \\
$\mathrm{MnO}$ & 0.02 & \\
$\mathrm{BaO}$ & 0.04 & \\
$\mathrm{Li}$ & 0.01 &
\end{tabular}

\section{Sample Preparation and Mechanical Property Testing}

Activators in solution ( $\left.\mathrm{KOH}, \mathrm{Na}_{2} \mathrm{SiO}_{3}\right)$, slurry (PSA) or powder form $\left(\mathrm{K}_{2} \mathrm{CO}_{3}, \mathrm{Na}_{2} \mathrm{CO}_{3}\right)$ were thoroughly mixed with the dry soil and the GGBS powder, before water was added to the mix to reach the target water content. Compacted cylindrical specimens in layers of $10 \mathrm{~mm}$ at the same fixed target dry densities $\rho_{\mathrm{d}}$ and water contents $\mathrm{w}$ (adjusted for solution water) for each soil were used, i.e. $\rho_{\mathrm{d}}=1.56 \mathrm{~g} / \mathrm{cm}^{3}$ and $\mathrm{w}=25 \%$ for the silt and $\rho_{\mathrm{d}}=1.43 \mathrm{~g} / \mathrm{cm}^{3}$ and $\mathrm{w}=40 \%$ for the clay. The selection of the compaction water content is of major relevance for the success of the treatment - enough water is needed for hydration reactions, but the effects of varied water contents on the results must also be considered, as the state of the soil (in particular the clay) and its undrained shear strength are related to the water content; depending on the plasticity characteristics of the soil, different water contents would affect the consistency/state of the soil. Here a constant water content of $40 \%$ was used for the clay mixes, as it is close to the plastic limit of most clay/binder mixes tested (except those with PSA or PSA $+\mathrm{Na}_{2} \mathrm{SiO}_{3}$ ) but ongoing tests are performed with different water contents using the same liquidity index across soil/binder samples, for uniform consistency.

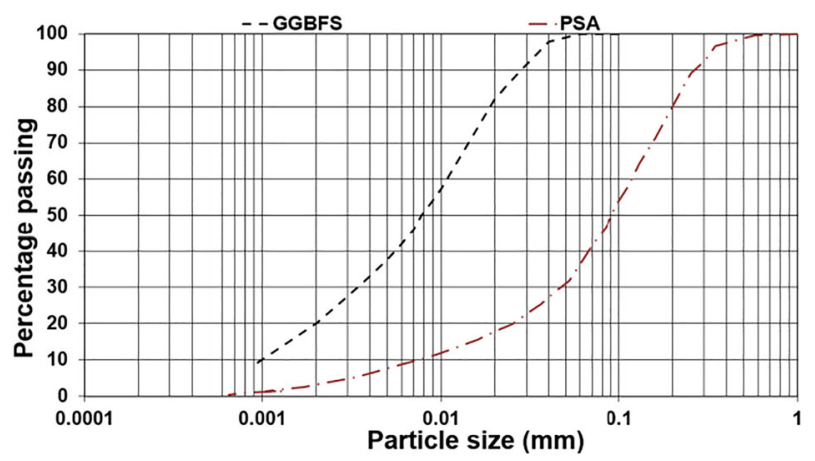

Fig. 1 Particle size distribution of GGBS and PSA 
The specimens were left to cure at ambient temperature as required. Silt specimens were cured at constant moisture wrapped in multiple layers of cling film and stored in a humidity controlled cabinet, as required for testing, namely 7 and 28 days of curing. For the clay, 7 days of constant moisture curing was followed by 21 days of water-curing, where the specimens still in moulds were placed on a porous stone standing on water and left to absorb water by capillary action; the latter curing method was adopted for the expansive clay soil to assess the effect of stabilisers on its swelling characteristics. At the end of the required curing periods and before testing, the mass of the specimens was recorded and their dimensions were measured using Vernier calipers.

UCS tests were performed at a constant rate of strain of $1 \mathrm{~mm} / \mathrm{min}$ with different mixes. As a minimum, duplicate to triplicate samples were prepared but many of the tests were replicated at later stages. Here, indicative results are presented to cover different types of binders and factors that could affect the outcomes, as explained in the "Mix Design" section above. For selected treatments from different types of binders/activator mixes further tests were then performed. These included indicative oedometer tests to determine the swelling and compressibility characteristics of specimens cured at constant moisture conditions for 7 days, and assessments of the durability of selected treatments to wetting and drying cycles. This work is ongoing to include further soil/binder mixes.

The durability to wetting-drying cycles testing was conducted as follows: UCS size soil specimens still in moulds (to avoid potential disintegration upon wetting), were weighed and placed on a porous stone in a tray with water. They were left to absorb water, turned upside down periodically to ensure uniform moisture distribution, until a target increase in moisture content of up to $55 \%$ the original compaction moisture content. Once the target mass had been achieved, the specimens were removed from the water and were kept in a humidity-controlled cabinet lying flat on their side, for at least 2-3 days for moisture homogenisation. The specimens were then left to air-dry below the compaction moisture content, until their $\%$ mass loss was equal to their $\%$ mass gain during the wetting stage. The procedure was repeated to result in three cycles of wetting-drying. The specimens were then brought back to their original compaction water content, and were subjected to UCS testing, to assess the effect of the wetting-drying cycles on their UCS.

\section{Material Analysis}

Material analysis was performed on selected treated soils at the end of two different curing periods ( 7 and 62 days of curing respectively) to assess the chemical and microstructural evolution in time. A first set of analyses was performed using an ARAMIS confocal Raman microscope (Horiba UK LTD) using a $633 \mathrm{~nm}$ laser, $50 \times$ objective, $600 \mathrm{l} / \mathrm{mm}$ grating, $100 \mu \mathrm{m}$ pinhole and 80-2060 $\mathrm{cm}^{-1}$ Raman shift range. The sample was illuminated in reflection mode using a tungsten light. This was followed by scanning electron microscopy (SEM) analysis where images were taken using FEG-SEM (Phenom Pharos, scanning electron microscope) after a small aliquot was placed on aluminium stubs and double-sided carbon tape (Ted Pella), $15 \mathrm{KV}$ and backscattered detector. On the same samples, elemental analysis (Energy dispersive spectroscopy EDS) was done using a Silicon drift detector (SDD) and 30s integration time. Finally, infrared spectra were taken using a Bruker alpha Fourier Transform Infrared spectrometer (FTIR) with a diamond attenuated total reflectance probe (ATR). Background signal was collected before each sample. Infrared spectra (40 times) were acquired from 400$4000 \mathrm{~cm}^{-1}$ and analysed using Ominc 7.0 (Thermo Scientific) software. 


\section{Results and Discussion}

\section{UCS Tests}

\section{Silt Soil}

Indicative results of the parametric study on silt are presented in Figs. 2 and 3. It can be seen that GGBS used as a control mix (before alkali stabilisation) was found to have a minor effect on the strength after 7 days; 28 days later however, due to the latent hydraulic nature of the GGBS the strength had approximately doubled compared to the untreated silt (Fig. 2(a)); this is the minimum requirement for a soil stabiliser to be considered as having an effect of the soil (strength gain requirements may of course be much higher depending on the application).

\section{Effect of Activator Type and Dosage}

All alkaline activators increased the strength of the silt but in comparison with alkaliactivated mixes with $\mathrm{Ca}(\mathrm{OH})_{2}$ (from PSA) and $\mathrm{KOH}$ acting as the sole base activators, the carbonates and silicate used on their own led to small strength increases (compare Fig. 2(a) with Fig. 2(b) and Fig. 3(a)). The carbonates are relatively weak activators compared to hydroxides and of lower alkalinity, so this was not a surprise. Lower strengths can be linked to the interaction of the carbonate ions $\left(\mathrm{CO}_{3}{ }^{2-}\right)$ from the carbonate activator with the calcium ions $\left(\mathrm{Ca}^{2+}\right)$ from the dissolved slag, favouring the development of calcium and mixed carbonates (e.g. sodium-calcium) instead of the formation of calcium silicate hydrate gels which are stronger cementing agents [42]. $\mathrm{Na}_{2} \mathrm{SiO}_{3}$ used in the same amount as the carbonates did not have a very pronounced effect on the strength of the soil compared to the carbonates. This was not expected as silicate activators are commonly used in alkali activated cements to lead to higher strengths. Conversely, when $\mathrm{Na}_{2} \mathrm{SiO}_{3}$ was used with $\mathrm{Ca}(\mathrm{OH})_{2}$ (from PSA) and $\mathrm{KOH}$ the effect was variable with generally modest early strength increases compared to the respective mixes without $\mathrm{Na}_{2} \mathrm{SiO}_{3}$ but with considerable differences in the 28-day strengths (and spectacular increases in two instances when $\mathrm{Na}_{2} \mathrm{SiO}_{3}$ was combined with $\mathrm{KOH}$ ).

Comparing Fig. 2(b) and 3(a) $\mathrm{KOH}$ used as the sole activator at the same percentage as PSA led to higher earlier strengths than PSA. However, after 28 days of curing, PSA activator mix strengths were very close - in several occasions higher - to those of the respective $\mathrm{KOH}$ mixes; the latter showed little strength evolution between 7 and 28 days; conversely PSA mixes kept gaining strength in time (this was not expected as according to the Authors' experience, PSA used as an alkali activator of GGBS in concrete cement [43, 44] gave instead high early strength gain with less strength evolution in later times; this could however be due to the relatively low PSA content used in the concrete mixes). The strength gains with only 3 to $6 \%$ PSA in the mixes were very considerable, namely, (a) for mixes without $\mathrm{Na}_{2} \mathrm{SiO}_{3}$ 17-20 and 30-60 times higher than that of silt for 7 and 28 days of curing respectively; (b) for mixes with $\mathrm{PSA}+\mathrm{Na}_{2} \mathrm{SiO}_{3} 22-62$ and 66-74 times higher that of silt for 7 and 28 days of curing respectively. As mixes with $\mathrm{Na}_{2} \mathrm{SiO}_{3}$ as the sole activator had only about 2-5 times the strength of the untreated silt, the considerable contribution of PSA to the strength gain is obvious.

Replacing partially the $\mathrm{KOH}$ by $\mathrm{K}_{2} \mathrm{CO}_{3}$ or otherwise keeping the same amount of $\mathrm{KOH}$ and adding carbonate led to lower strengths (see Fig. 2(b) vs (c)). Conversely, 

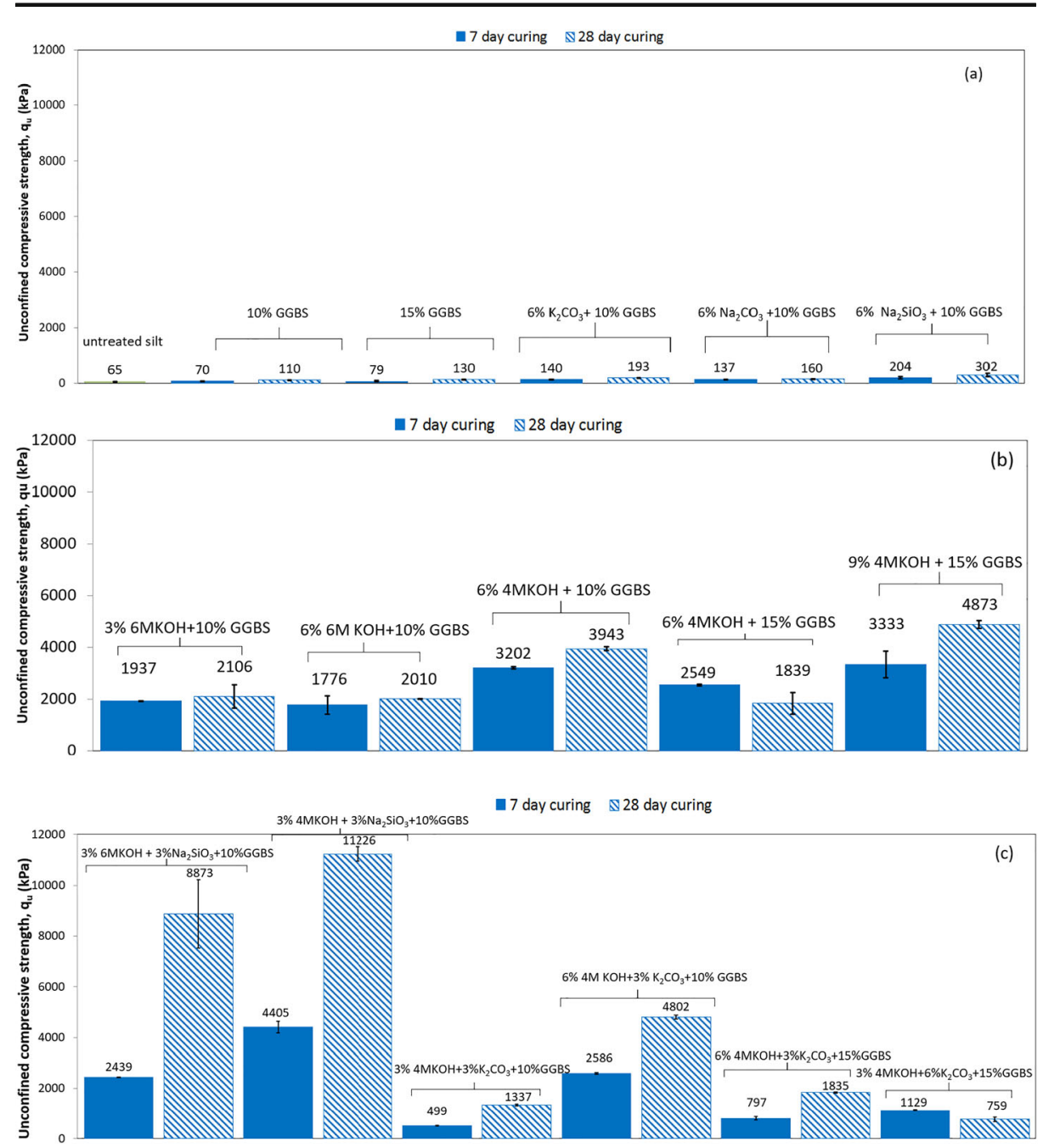

Fig. 2 Indicative UCS results for silt and commercial alkalis: (a) control mixes and alkali salts only; (b) mixes with $\mathrm{KOH}$ only; (c) Mixes with $\mathrm{KOH}$ and alkali salts

adding carbonates or silicate in the PSA mix led to clearly improved strengths (see Fig. 3(a) vs (b)) with a dramatic increase in the 28-day strength when PSA is used with $\mathrm{Na}_{2} \mathrm{CO}_{3}$ and $15 \%$ of GGBS; in some cases PSA-carbonate mixes outperformed PSA$\mathrm{Na}_{2} \mathrm{SiO}_{3}$ mixes. There is however an example of strength reversal in a mix with PSA of low content and $\mathrm{Na}_{2} \mathrm{CO}_{3}$.

\section{Effect of Solution Molarity}

Increasing $\mathrm{KOH}$ molarity from 4 to $6 \mathrm{M}$ (Fig. 2(b)-(c)) consistently led to a decrease in strength of silt mixes; further material analysis is required to establish the reason for this reduction and the optimal molarity but overall $4 \mathrm{M} \mathrm{KOH}$ mixes were successful in giving some of the highest strengths. 


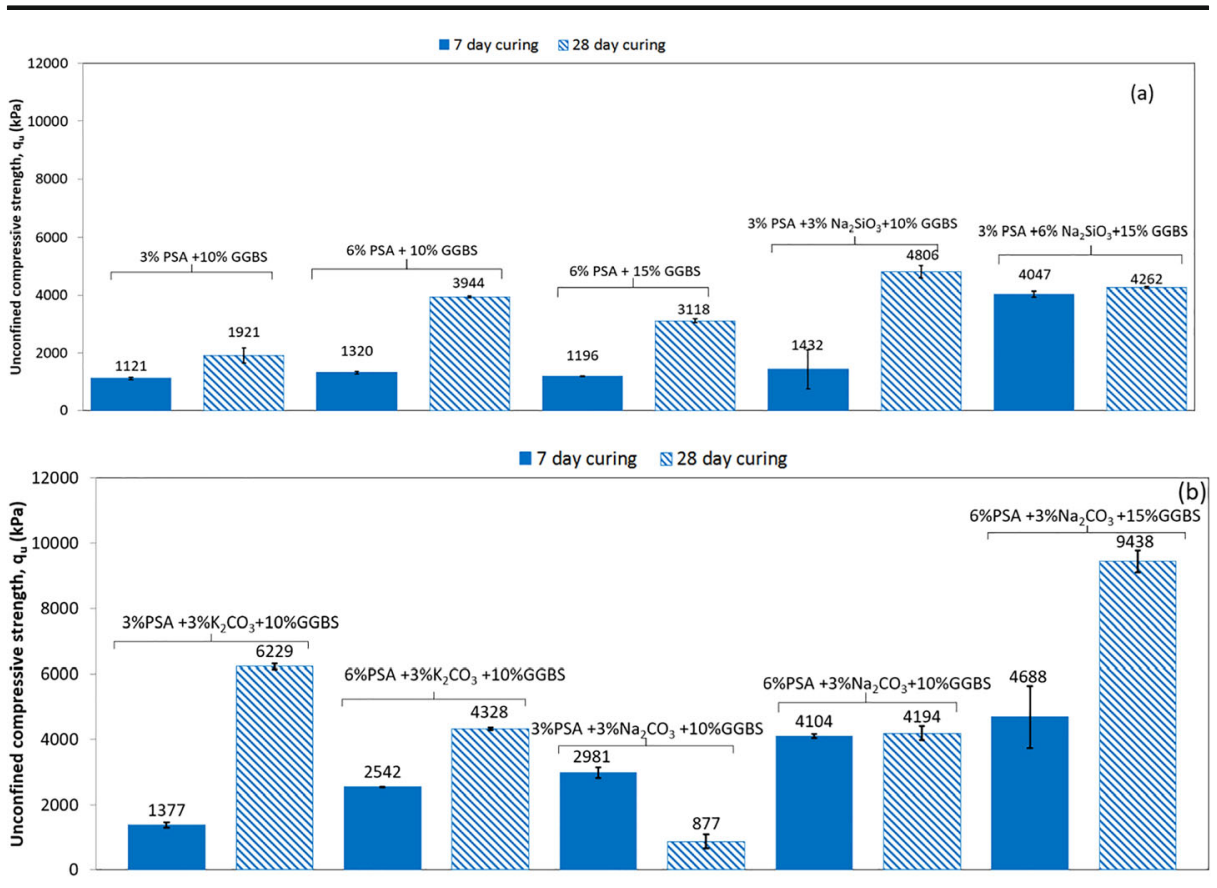

Fig. 3 Indicative UCS results for silt and PSA used as activator: (a) mixes with PSA only or PSA and sodium silicate; (b) mixes with PSA and carbonates

\section{Effect of Activator/Precursor Ratio}

The effect of increasing the amount of precursor without increasing the activator can be seen in Fig. 2(b) comparing the strengths of mixes with $6 \% \mathrm{KOH}$ activating $10 \%$ GGBS vs $6 \% \mathrm{KOH}$ activating $15 \%$ GGBS; the latter strengths are lower with an apparent strength reversal (the 28 day-curing strength is lower than the 7 day-curing strength). This is difficult to explain but it was noted in some other occasions -see e.g. the last mix at the right-hand side in Fig. 2(c) and a few other mixes not shown here for brevity. Moreover, some of the replicated specimens with $\mathrm{KOH}$ only (supplied at 3-6\% with GGBS of 10-15\% per dry soil mass) broke during handling after 28 day curing which again shows some variability in the long-term curing response. Thus, although the UCS test is a crude quick test with little control on the testing conditions and this could have led to a certain variability in the results due to the poor accuracy of the test, this potential reversal in strength appears to be a trend which needs further investigation. Increasing the $\mathrm{KOH}$ content at the same time as increasing the GGBS content (i.e. keeping the same ratio of activator/precursor=0.6) increased in particular the 28-day strength. Conversely, increasing the GGBS amount while keeping the activator content constant or increasing the activator content without increasing the GGBS content generally led to decreased strengths emphasising the effect of the activator/precursor ratio (for PSA, increasing the PSA content also increases aluminosilicate precursor content).

Analysis of the Results To identify the significant factors amongst molarity, activator dosage and activator/precursor ratio affecting the UCS of the mixes described above, and design future tests accordingly, factorial design analyses using R software were performed on the strengths of AAC systems with $\mathrm{KOH}$, for which the majority of data combinations was available, i.e. the 
7- and 28-day curing results presented in Fig. 2(b)-(c). Analyses were in the form of $\mathrm{n}^{\mathrm{k}}$ with the number of factors $k=3$ namely "Molarity", Activator dosage ("AA") and Activator/GGBS ratio ("AA_GGBS"), for two respective levels (n=2) of the factors, i.e. -1 (low) and +1 (high) levels. Before performing further statistical analysis, the data was inspected in different plots (boxplots, histograms, interaction plots). These details are not shown here for brevity. Based on the boxplots all factors appeared to affect the results to some extent; therefore, strength variation might not be due to sample randomization only, and these factors might be able to explain the variation. Variances were not homogeneous; this was the case for all factors. Interaction plots showed little interaction between factors (plot lines did not intersect on any occasion although AA and AA_GGBS lines were not exactly parallel, showing some small interaction); therefore, the main effects were considered in the ANOVA model. Histogram and boxplots showed that the distribution was not normal for either the 7- or 28-day curing samples, although for the quantile-quantile plot of the 7-day results, normality could be considered as a reasonable assumption (with some deviations from normality), unlike for the 28 day quantile-quantile plot; the Shapiro-Wilk test results corroborated this. The homogeneity of variances hypothesis was rejected by the Fligner-Killeen test for both the 7- and 28-day curing samples. Considering this, and also the relatively small sample and the unbalanced data (i.e. unequal numbers of observations for each factor level), Kruskal-Wallis non-parametric analysis was performed in addition to ANOVA. The ANOVA and Kruskal-Wallis results shown in Table 2 are consistent for the 7-day curing but there is a different relevance order of the significant factors in the 28-day sample; however significant factors are the same.

\section{Clay Soil}

Figure 4 shows indicative results of 28 day-cured clay. There are no results for the untreated soil, as the specimens collapsed upon soaking; the fact that all treated soil samples withstood soaking shows that all treatments were successful in cementing the soil. The overall trends are generally similar to the AA-silt mixes, i.e. the 28-day results are sensitive to the molarity (here mixes with $6 \mathrm{M} \mathrm{KOH}$ only, performed less well than $\mathrm{Na}_{2} \mathrm{SiO}_{3}$ only mixes and in all instances mixes of $4 \mathrm{M} \mathrm{KOH}$ gave higher strengths than the respective $6 \mathrm{M} \mathrm{KOH}$ mixes) and to the ratio of activator/GGBS. Mixes with $\mathrm{KOH}$ and $\mathrm{Na}_{2} \mathrm{SiO}_{3}$ had lower strengths than the respective mixes with $\mathrm{KOH}$ only, showing that $\mathrm{Na}_{2} \mathrm{SiO}_{3}$ had a negative effect -however this could be due to the insufficient amount of GGBS provided. For the clay, PSA is shown to be clearly more successful compared to mixes with $\mathrm{KOH}$ provided at the same dosage per dry soil mass; this is probably due to direct modification/pozzolanic reactions of the lime with the clay (in addition to activating the GGBS). Finally, the combination of PSA with $\mathrm{K}_{2} \mathrm{CO}_{3}$ was successful in further increasing the strength by approximately $49 \%$ compared to the mix with PSA only.

Table 2 Relevance order of factors considered (significant factors at 95\% confidence level)

\begin{tabular}{|c|c|c|}
\hline Curing time & ANOVA & Kruskal-Wallis non-parametric analysis \\
\hline 7 days & $\begin{array}{c}\boldsymbol{A} \boldsymbol{A}(p \text {-value }=0.003929)>\boldsymbol{A} \boldsymbol{A} \_\boldsymbol{G} \boldsymbol{G} \boldsymbol{B} \boldsymbol{S} \\
\quad(p \text {-value }=0.017740)\end{array}$ & $\begin{array}{c}\boldsymbol{A} \boldsymbol{A}(p \text {-value }=0.004326)>\boldsymbol{A} \boldsymbol{A}_{-} \boldsymbol{G} \boldsymbol{G} \boldsymbol{B} \boldsymbol{S} \\
\quad(p \text {-value }=0.02557)\end{array}$ \\
\hline 28 days & $\begin{array}{l}\boldsymbol{A} \boldsymbol{A} \_\boldsymbol{G} \boldsymbol{G B S}(p \text {-value }=0.00005361)> \\
\boldsymbol{M} \text { olarity }(p \text {-value }=0.03717)>\boldsymbol{A A} \\
(\mathrm{p} \text {-value }=0.003208)\end{array}$ & $\begin{array}{c}\boldsymbol{A} \boldsymbol{A}(p \text {-value }=0.003208)=\boldsymbol{A} \boldsymbol{A} \_\boldsymbol{G} \boldsymbol{G B S} \\
(p \text {-value }=0.003208)>\text { Molarity } \\
(p \text {-value }=0.03717)\end{array}$ \\
\hline
\end{tabular}




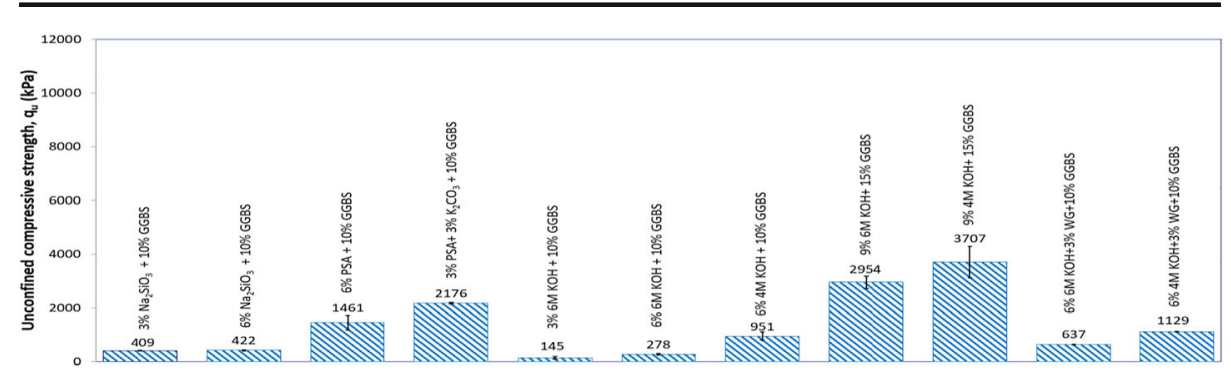

Fig. 4 Indicative UCS results for a clay soil (21 days water curing after 7 days of constant moisture curing)

The very good overall performance of the PSA is consistent with a number of previous studies by the Authors, where the material was used either as an activator of GGBS or otherwise fully or partially replacing cement or lime. PSA led to similar or better strengths than cement or lime for a number of soils, in particular different clays, silt and the paper sludge itself (from which PSA originates) which could then be used as a fill material instead of soil $[35,45,52,53]$.

\section{Oedometer Testing Results}

Table 3 shows indicative oedometer results in terms of (a) swelling upon the saturation stage prior to compression and (b) compression index $\mathrm{C}_{\mathrm{c}}$ (for effective stress ranging up to $400 \mathrm{kPa}$ ) for silt treated with selected binder mixes. All activator mixes reduced the volumetric changes of the soil, either upon water induced swelling or compression, showing that some cementation was achieved to one or another extent. The effects were more pronounced for the clay soil, where mineralogy modification reactions with the clay occur in the presence of stabilisers, resulting in less swelling. Overall, PSA-containing mixes were again of the most successful for the clay soil. Note that the Clay_6\% $\mathrm{K}_{2} \mathrm{CO}_{3}+10 \% \mathrm{GGBS}$ results are from a parallel study, retrieving the chemical substances from waste materials; thus, in this mix, $\mathrm{K}_{2} \mathrm{CO}_{3}$ was crude $\mathrm{K}_{2} \mathrm{CO}_{3}$ obtained by banana peel incineration.

\section{Preliminary Tests on Durability to Wetting and Drying Cycles}

Figure 5 shows UCS strengths of selected treated silt specimens after three cycles of drying and wetting. The PSA-based binders performed very well after the cycles of drying and wetting, and interestingly, strength gains of $17.8 \%$ and $3.8 \%$ were recorded for the $6 \%$ PSA $+10 \%$ GGBS and the $3 \% \mathrm{PSA}+3 \% \mathrm{Na} 2 \mathrm{SiO} 3+10 \%$ GGBS mix respectively. Conversely samples with $\mathrm{KOH}$ showed strength loss, i.e. $13.4 \%$ for the sample containing only $\mathrm{KOH}$ and $50 \%$ loss for the sample containing $\mathrm{KOH}$ together with $\mathrm{K}_{2} \mathrm{CO}_{3}$. It is notable however that unpublished research by the authors on lime-treated clay soils also showed reductions of UCS of up to $50 \%$ after 3-4 cycles of wetting and drying of unconfined samples. Silt samples with $\mathrm{K}_{2} \mathrm{CO}_{3}$ only $\left(6 \% \mathrm{~K}_{2} \mathrm{CO}_{3}+10 \% \mathrm{GGBS}\right)$ and $\mathrm{Na}_{2} \mathrm{CO}_{3}$ only $\left(6 \% \mathrm{Na}_{2} \mathrm{CO}_{3}+10 \%\right.$ GGBS) disintegrated during the durability testing, hence no UCS measurements were possible. Similarly, a series of samples (not shown here for brevity) treated with $\mathrm{K}_{2} \mathrm{CO}_{3}$ or $\mathrm{K}_{2} \mathrm{CO}_{3}$ partly replaced by $\mathrm{KOH}$, cured at constant moisture for seven days and then subjected to water curing for UCS testing, became very soft after wetting, resulting in very low UCS ( $q_{u}$ ranging $10-25 \mathrm{kPa}$ ). This is unlike selected samples treated with PSA activator mixes (also including PSA- $\mathrm{K}_{2} \mathrm{CO}_{3}$ ) subjected to durability testing and which performed consistently well, as did the PSA-treated silt samples. A detailed durability study and supporting material analysis for all mixes is beyond the scope of this paper and will be the focus of future work. 
Table 3 Indicative oedometer testing results

\begin{tabular}{|c|c|c|}
\hline Soil/soil mix & Volumetric swelling strain, $\varepsilon_{\mathrm{V}}(\%)$ & C Compression index, $\mathrm{C}_{\mathrm{c}}$ \\
\hline Untreated silt & 2.3 & 0.08 \\
\hline Silt_6\% $\mathrm{Na}_{2} \mathrm{SiO}_{3}+10 \%$ GGBS & 0.01 & 0.07 \\
\hline Silt_ $6 \% \mathrm{~K}_{2} \mathrm{CO}_{3}+10 \% \mathrm{GGBS}$ & 0.9 & 0.07 \\
\hline Silt_6\% 4M KOH $+3 \% \mathrm{~K}_{2} \mathrm{CO}_{3}+10 \% \mathrm{GGBS}$ & 0.04 & 0.02 \\
\hline Untreated clay & 28.1 & 0.49 \\
\hline Clay_10\% PSA & 0.16 & 0.02 \\
\hline Clay_6\% PSA $+10 \%$ GGBS & 0.15 & 0.06 \\
\hline Clay_6\% $\mathrm{Na}_{2} \mathrm{SiO}_{3}+10 \% \mathrm{GGBS}$ & 0.15 & 0.1 \\
\hline Clay_6\% PSA $+3 \% \mathrm{Na}_{2} \mathrm{SiO}_{3}+15 \%$ GGBS & 0.02 & 0.06 \\
\hline Clay_6\% $\mathrm{K}_{2} \mathrm{CO}_{3}+10 \%$ GGBS & 2.8 & 0.19 \\
\hline Clay_3 $\%$ PSA $+3 \% \mathrm{~K}_{2} \mathrm{CO}_{3}+10 \%$ GGBS & 0.08 & 0.025 \\
\hline
\end{tabular}

\section{Selected Material Analyses}

For the material analyses the results refer to untreated silt (control sample) and AAC-silt treated with $3 \%$ PSA $+3 \% \mathrm{Na}_{2} \mathrm{SiO}_{3}+10 \%$ GGBS (Sample 1); $6 \%$ PSA + $10 \%$ GGBS (Sample 2); $6 \% 4 \mathrm{M} \mathrm{KOH}$ $+10 \%$ GGBS (Sample 3); and 3\% 4M KOH + 3\% $\mathrm{K}_{2} \mathrm{CO}_{3}+10 \% \mathrm{GGBS}$ (Sample 4).

The Raman set of analyses showed that spectra were dominated by silicon oxides for the control sample, which was expected, but also for all treated samples tested after 1 day, 7 and 62 days after treatment. The silicate/quartz was too strong, dominating the spectra, thus making the detection of other phases difficult. Indicative results are shown in Figure 6 for 1 day cured sample 2 - the other samples and subsequent curing times showed little differences.

Figure 7(a)-(d) shows FTIR spectra of the untreated soil (control) and the four treated samples; at the right-hand side of the figures, details are given of the absorption bands where carbonates (Zoom 1) and silicate-aluminosilicate groups (Zoom 2) can be found. It is notable that the $\mathrm{OH}$ band at
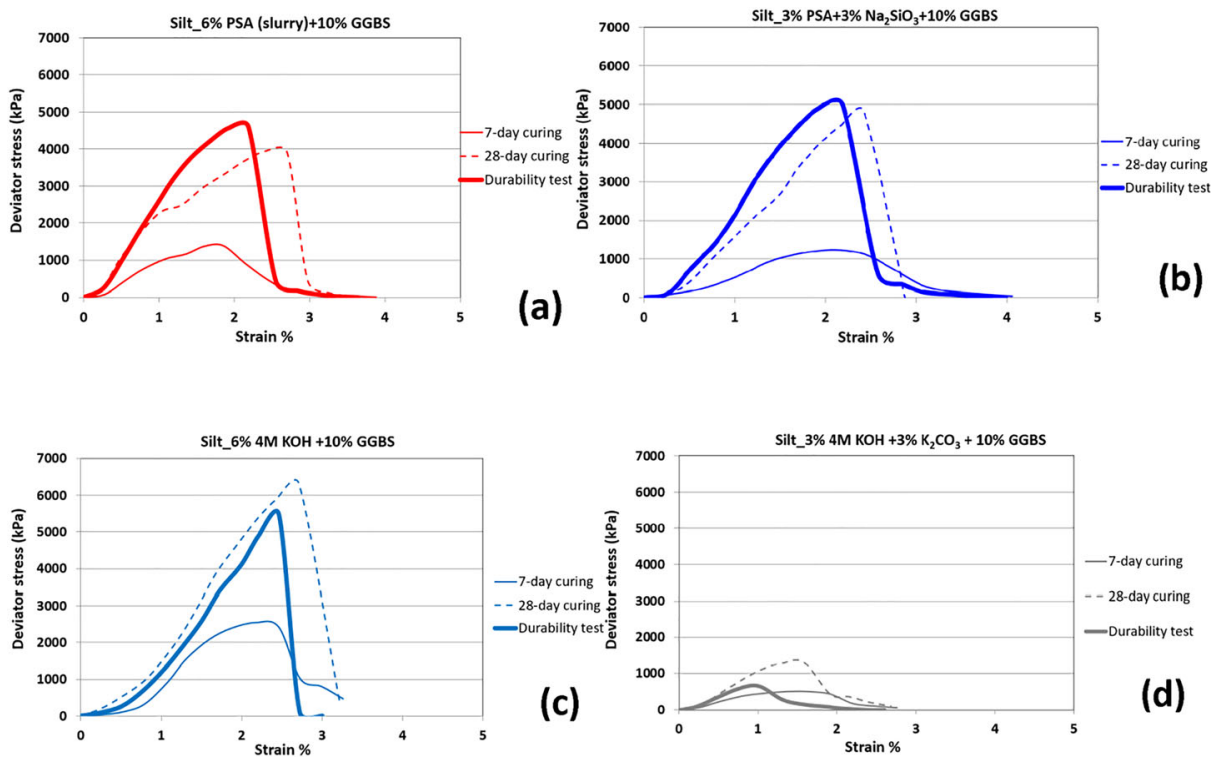

Fig. 5 Indicative durability results for silt soil treated with (a) $6 \%$ PSA $+10 \%$ GGBS; (b) $3 \%$ PSA $+3 \%$ $\mathrm{Na}_{2} \mathrm{SiO}_{3}+10 \%$ GGBS; (c) $6 \% 4 \mathrm{M} \mathrm{KOH}+10 \% \mathrm{GGBS}$; (d) $3 \% 4 \mathrm{M} \mathrm{KOH}+3 \% \mathrm{~K}_{2} \mathrm{CO}_{3}+10 \% \mathrm{GGBS}$ 


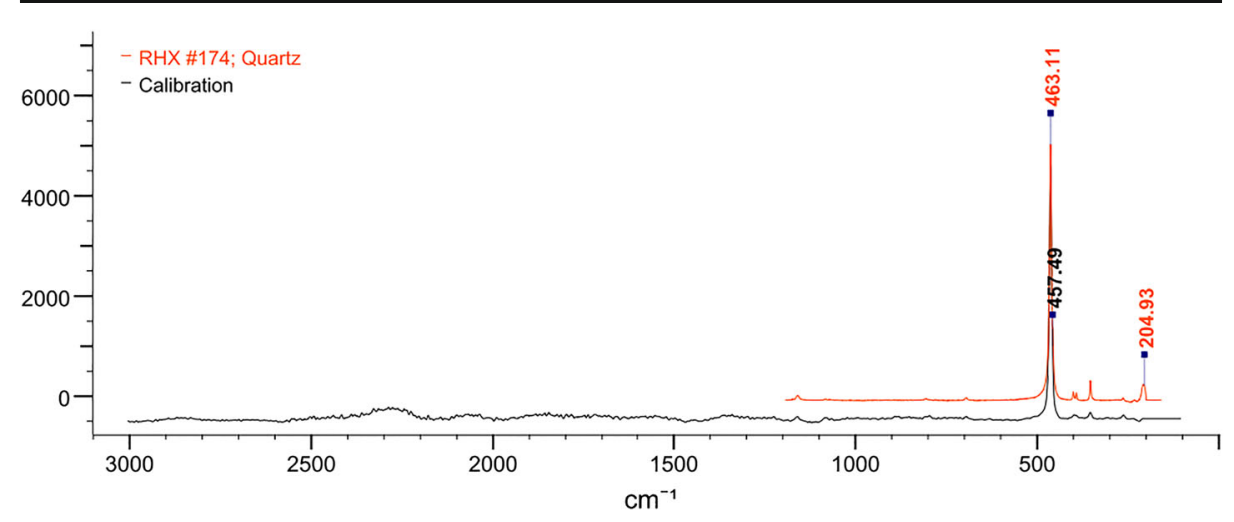

Fig. 6 Indicative Raman spectroscopy results for silt soil treated with $6 \%$ PSA $+10 \%$ GGBS after 1 day of curing

approximately $3650 \mathrm{~cm}^{-1}$ is not visible in any of the samples, which indicates that almost no hydroxides are present, although Samples 3-4 originally contained $\mathrm{KOH}$ and the slurry PSAtreated samples 1 and 2 contained $\mathrm{Ca}(\mathrm{OH})_{2}$. There are small changes in the zoomed silicatealuminosilicate spectra, with some small peak shifts or new peaks appearing, which could be linked with reaction product formation but most notable are the signals typical of $\mathrm{C}-\mathrm{O}$ stretching vibrations in carbonates in the range $1400-1600 \mathrm{~cm}^{-1}$, indicating $\mathrm{CO}_{3}^{-2}$ formation in all samples, which increases as the time passes, consistent with results in [26]; note that the observed peaks at 14201450 and $870 \mathrm{~cm}^{-1}$ are both present in calcite. This indicates the formation of calcium carbonate, which could be partly attributed to some carbonation of the GGBS reported in the literature [46]. As in Raman analysis, there was a high match of the treated and control samples ( $91 \%$ match), as the spectra were dominated by the Si-O-Si bonds with a characteristic strong band centered around 1100 $\mathrm{cm}^{-1}$, typical for inorganic silicates and alumino-silicates spectra; the presence of quartz as the main crystalline compound was confirmed from a number of characteristic bands (e.g. 1145, 1084, 796$\left.778,697,522,460 \mathrm{~cm}^{-1}[46]\right)$. Further analysis was therefore performed by subtracting from the collected spectra to the spectra of Quartz from the RRUFF database; when this was done, the 62-day results of Sample 1 and Sample 2 which contained PSA (not shown here for brevity) showed a good match with regular cement (68.14\%) which could explain the high strength gain in time and good durability of these two samples, shown in Fig. 5 (a) and (b).

Figure 8(a-e) shows indicative SEM-EDS results of the untreated and treated silt; EDS analysis spectra are taken from a number of sites on the four treated soil samples, including spectra of background locations representative of the largest part of the respective particle, and spectra of sites where different features can be seen in the SEM. These consistently indicated that for all samples the main element in background sites is $\mathrm{Si}$ with significant $\mathrm{O}_{2}$ peaks, which is consistent with the FTIR and Raman analyses (showing high silica content). The previous findings on the presence of calcium carbonate/calcite are also corroborated, e.g. on site 3 of sample 2, showing $\mathrm{C}, \mathrm{Ca}$ and $\mathrm{O}$ (the morphology of the crystals also indicates calcite); possible formation of calcium silicate hydrates is shown from sample 1 site 3 spectra with $\mathrm{Ca}$, Si and $\mathrm{O}$ peaks with possible integration of magnesium into the $\mathrm{C}-\mathrm{S}-\mathrm{H}$ structure as some $\mathrm{Mg}$ peaks are seen, due to the composition of PSA and GGBS. Note that the Br peaks shown are believed to be a misidentification of the software giving $\mathrm{Br}$ instead of $\mathrm{Al}$ (which would imply formation of $\mathrm{C}-\mathrm{A}-\mathrm{S}-\mathrm{H}$ ); this misidentification has been reported in the literature [47]. On the other hand, sites 4 and 5 of samples 3 and 4 in addition to $\mathrm{Ca}$, $\mathrm{Si}$ and $\mathrm{O}$ peaks also show K peaks consistent with the $\mathrm{KOH}$ and $\mathrm{K}_{2} \mathrm{CO}_{3}$ activators used. 


\section{Discussion}

The above analysis showed a number of successful AAC systems for soil stabilisation based on GGBS activation, for which there is experience for its successful use in concrete cements. GGBS is now a widely used by-product and an established commercially supplied low-cost supplementary cement material (SCM) in blended Portland cements for concrete. GGBS AAC systems for concrete have been shown to have good durability, for instance against sulphate or acid attack, and other
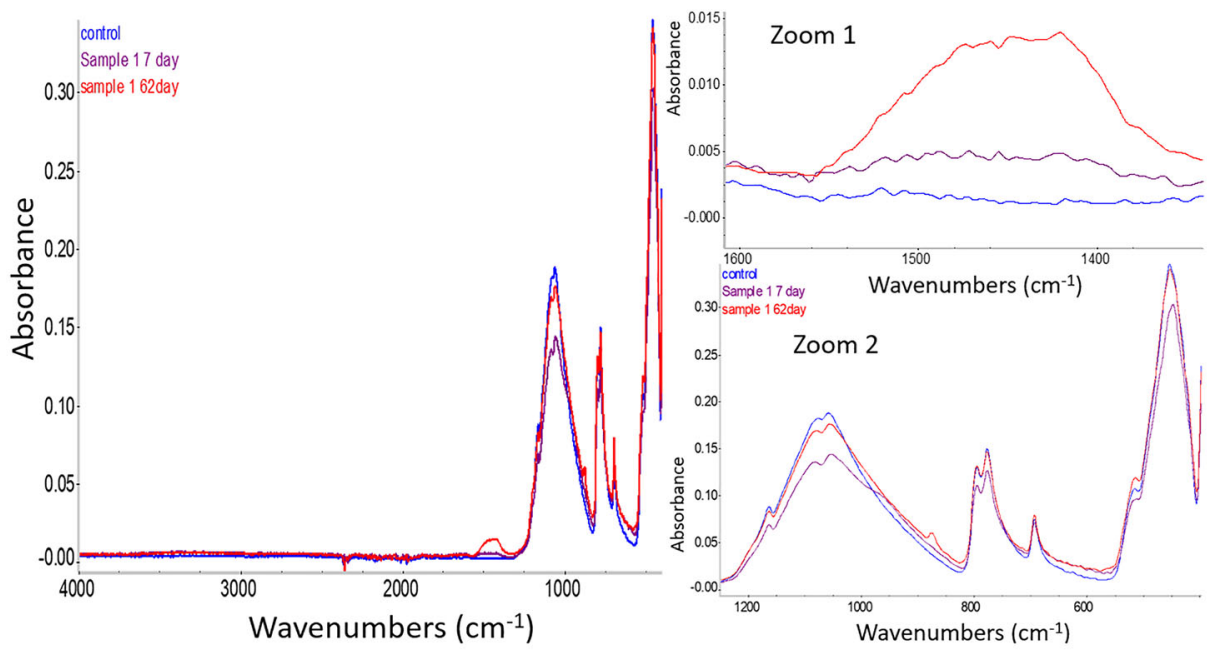

(a)
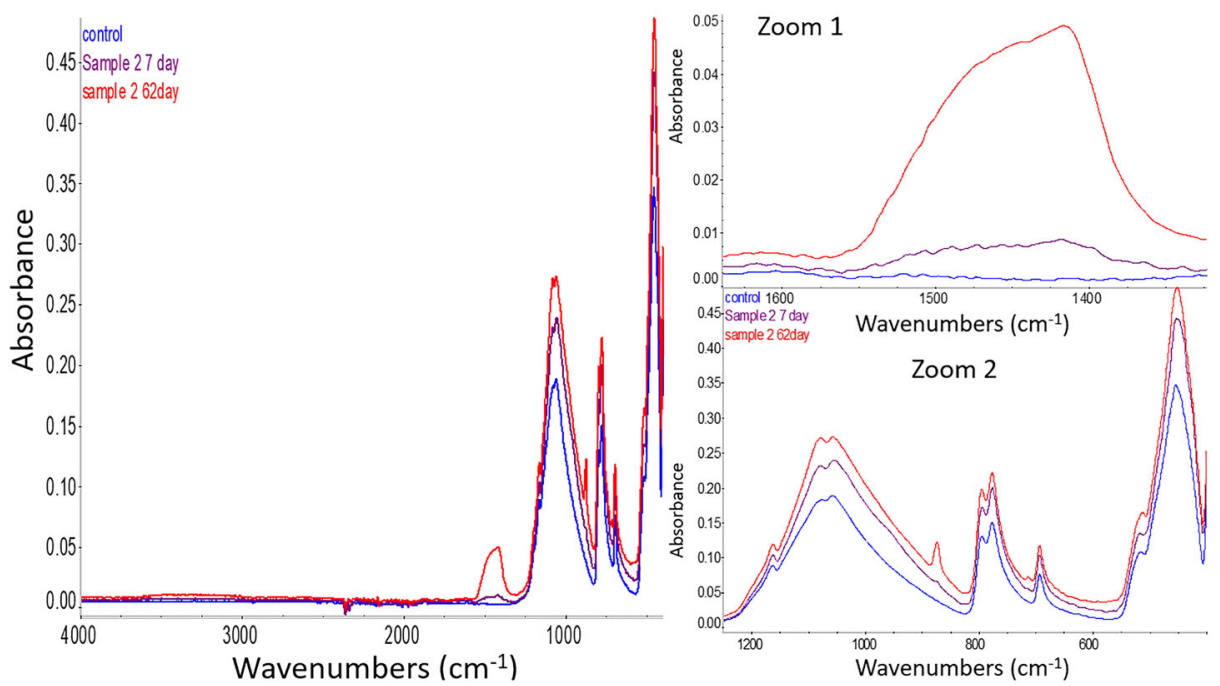

(b)

Fig. 7 Indicative FTIR results for silt soil (a) Sample 1: treated with 3\% PSA $+3 \% \mathrm{Na}_{2} \mathrm{SiO}_{3}+10 \%$ GGBS; (b) Sample 2: treated with 6\% PSA $+10 \%$ GGBS; (c) Sample 3: treated with $6 \% 4 \mathrm{M} \mathrm{KOH}+10 \% \mathrm{GGBS}$; and (d) Sample 4: treated with $3 \% 4 \mathrm{M} \mathrm{KOH}+3 \% \mathrm{~K}_{2} \mathrm{CO}_{3}+10 \% \mathrm{GGBS}$ 

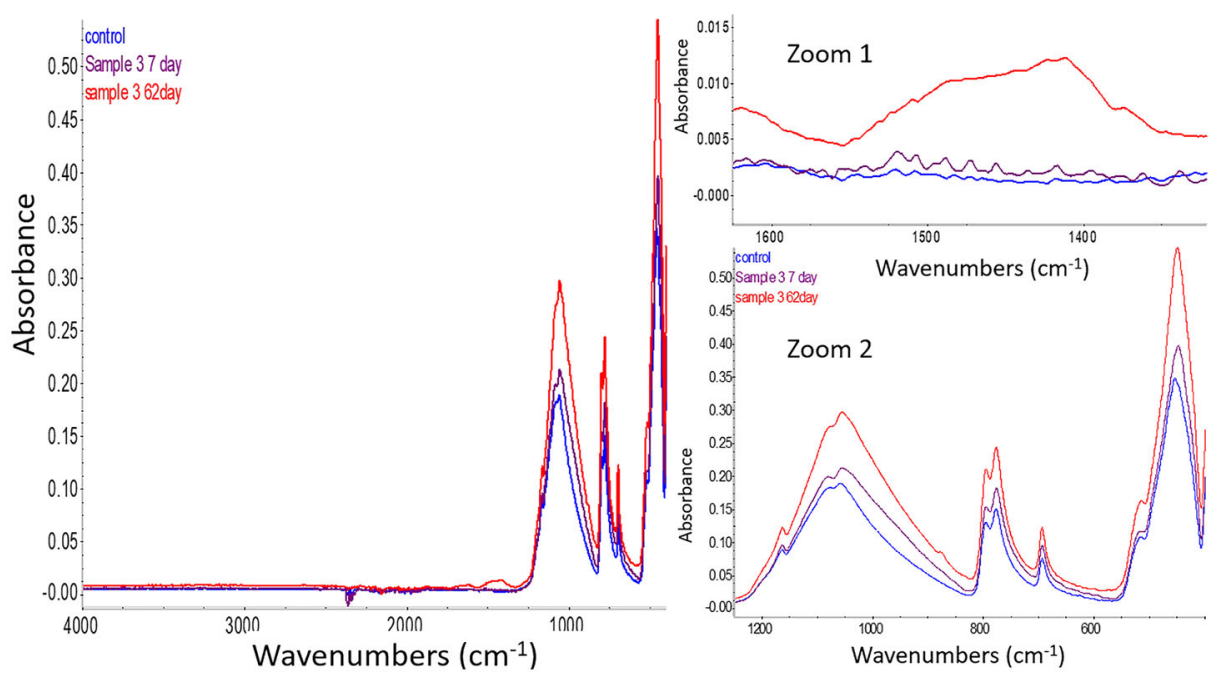

(c)
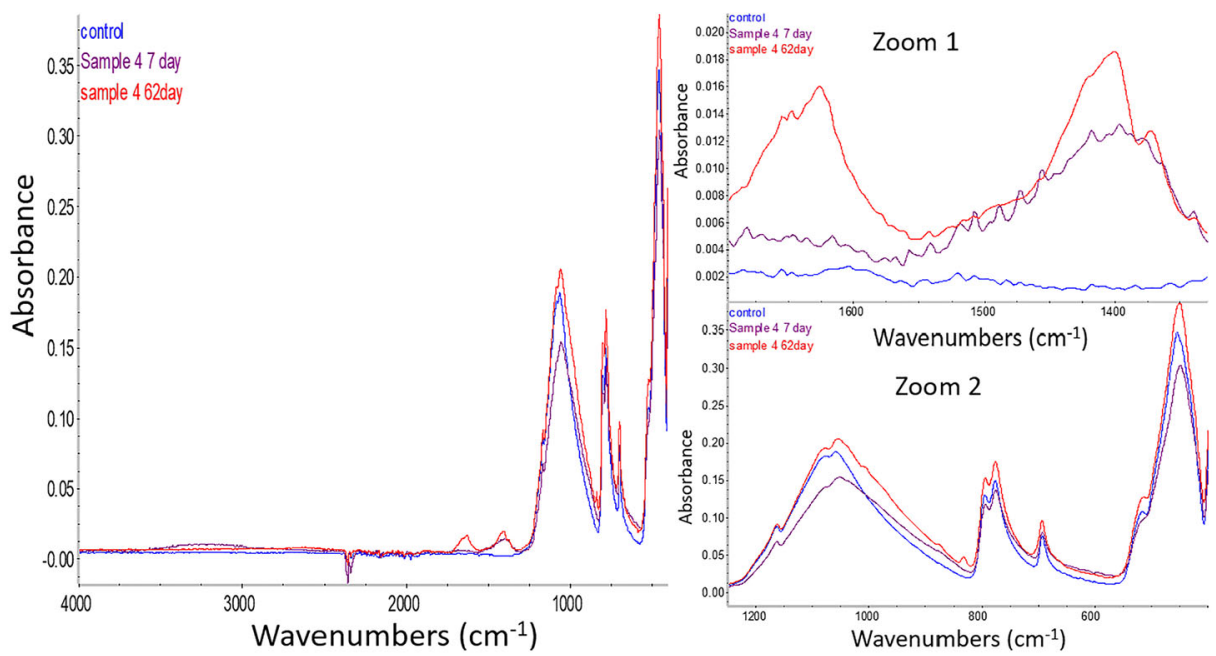

(d)

Fig. 7 (continued)

chemically aggressive environments [44, 48, 49]; for ground improvement GGBS has been used in blends with calcium-based soil stabilisers to counteract effects of sulphate-induced heave [50]. There is therefore good potential for the use of GGBS in AAC if the right AAC system is chosen. The good durability would contribute to the overall sustainability of the AAC soil stabilisation. In terms of supply availability, a global GGBS production of 300 million tons annually has been reported [48], although its established use as SCM in blended Portland cements, in addition to any local trends in the steel industry activities, could place a limit on its availability for AAC, especially as its use as SCM is much more widely understood by industry and hence established, compared to its use in the production of AAC. 
A major advantage of AAC is the possibility to include a wide variety of waste materials in the binder mix. In this work one waste material, PSA, was directly introduced in the mixes as alternative source of $\mathrm{Ca}(\mathrm{OH})_{2}$, whilst other alkali activators which were commercially supplied in this study, can be extracted from waste to reduce costs, as activator mix is the most expensive component in the AAC system.

PSA is disposed of in landfills in a large part. In the UK, the increasing amount of PSA classified as waste (with 4 out 40 paper mills reported to generate 140 ktonnes of PSA annually $[38,51])$, has caused environmental concerns and high costs to industry due to UK landfill tax (£96.70/t and $£ 3 / \mathrm{t}$ for active and inactive waste respectively in 2021). PSA has
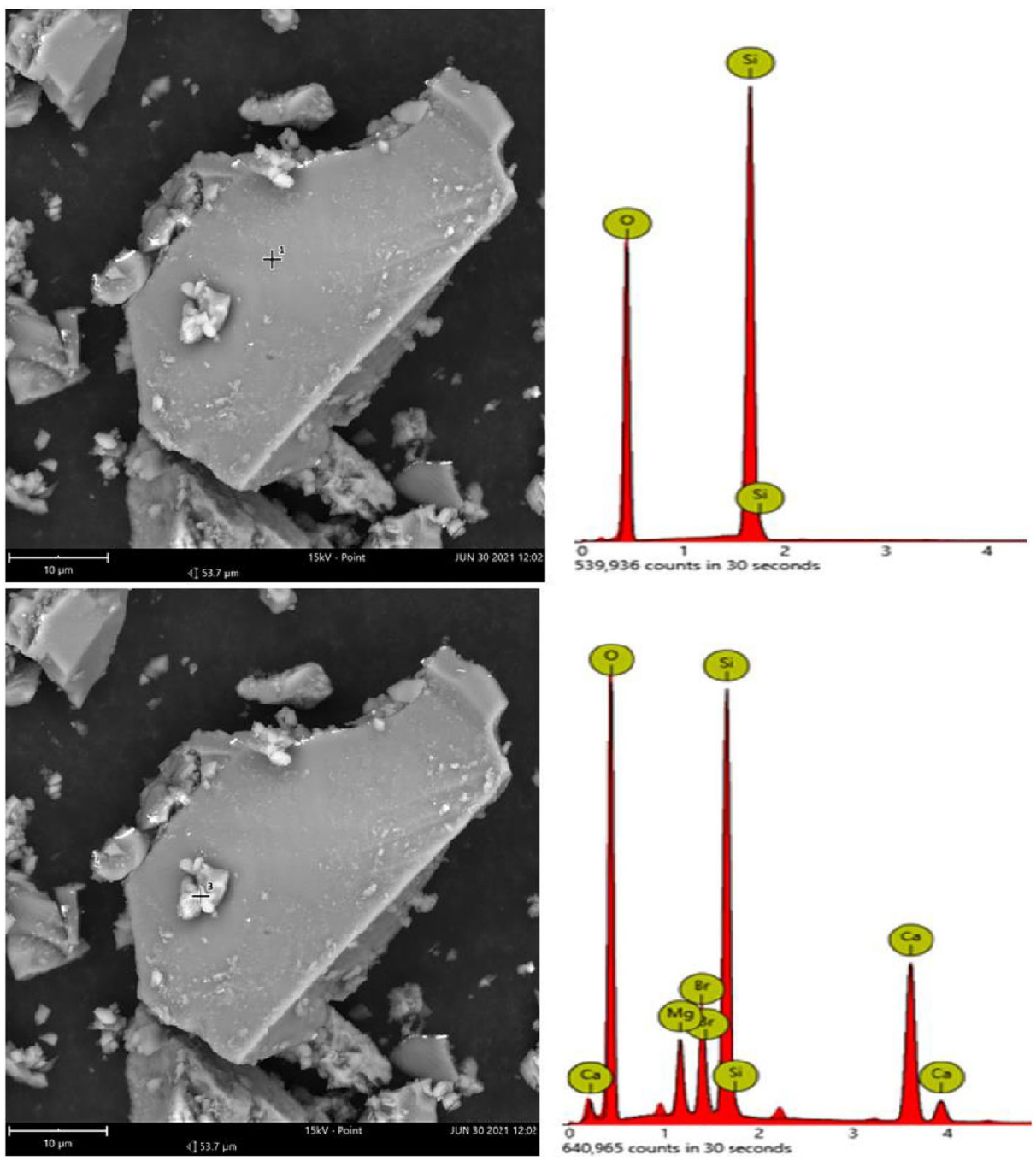

(a)

Fig. 8 Indicative SEM-EDS results for silt soil: (a) Sample 1: treated with $3 \%$ PSA $+3 \% \mathrm{Na}_{2} \mathrm{SiO}_{3}+10 \%$ GGBS (7-day curing); (b) Sample 2: treated with 6\% PSA +10\% GGBS (62-day curing); (c) Sample 3: treated with 6\% $4 \mathrm{M} \mathrm{KOH}+10 \%$ GGBS (7-day curing); (d) Sample 4: treated with $3 \% 4 \mathrm{M} \mathrm{KOH}+3 \% \mathrm{~K}_{2} \mathrm{CO}_{3}+10 \%$ GGBS (7day curing) and (e) Sample 4: treated with $3 \% 4 \mathrm{M} \mathrm{KOH}+3 \% \mathrm{~K}_{2} \mathrm{CO}_{3}+10 \% \mathrm{GGBS}$ (62-day curing) 

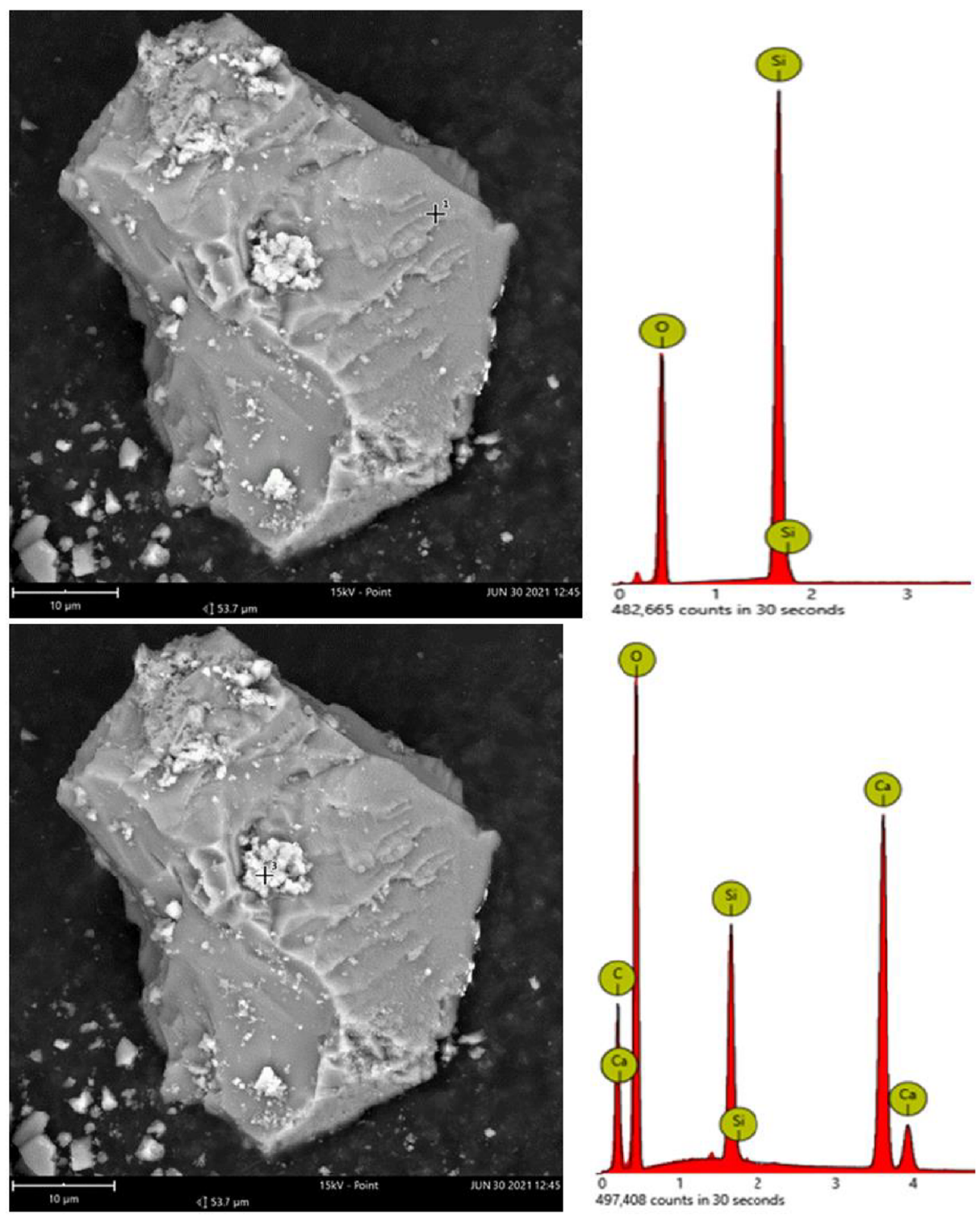

(b)

Fig. 8 (continued)

shown great promise as an alternative to lime for soil stabilisation [35, 45, 52, 53]. Here, its good performance in alkali activator mixes was also proven, as it led to early strength gains, continued increase in strengths upon curing, comparable to other established and more caustic activators such as $\mathrm{KOH}$, and showed the best durability to wetting-drying. The use of PSA for soil stabilisation is thus a promising outlet route for this waste material. Moreover, the fact that PSA gave good results without being combined with $\mathrm{Na}_{2} \mathrm{SiO}_{3}$ is positive, as $\mathrm{Na}_{2} \mathrm{SiO}_{3}$ also requires high energy input for its production $\left(>1300^{\circ} \mathrm{C}\right)$, as does cement, and can be difficult 

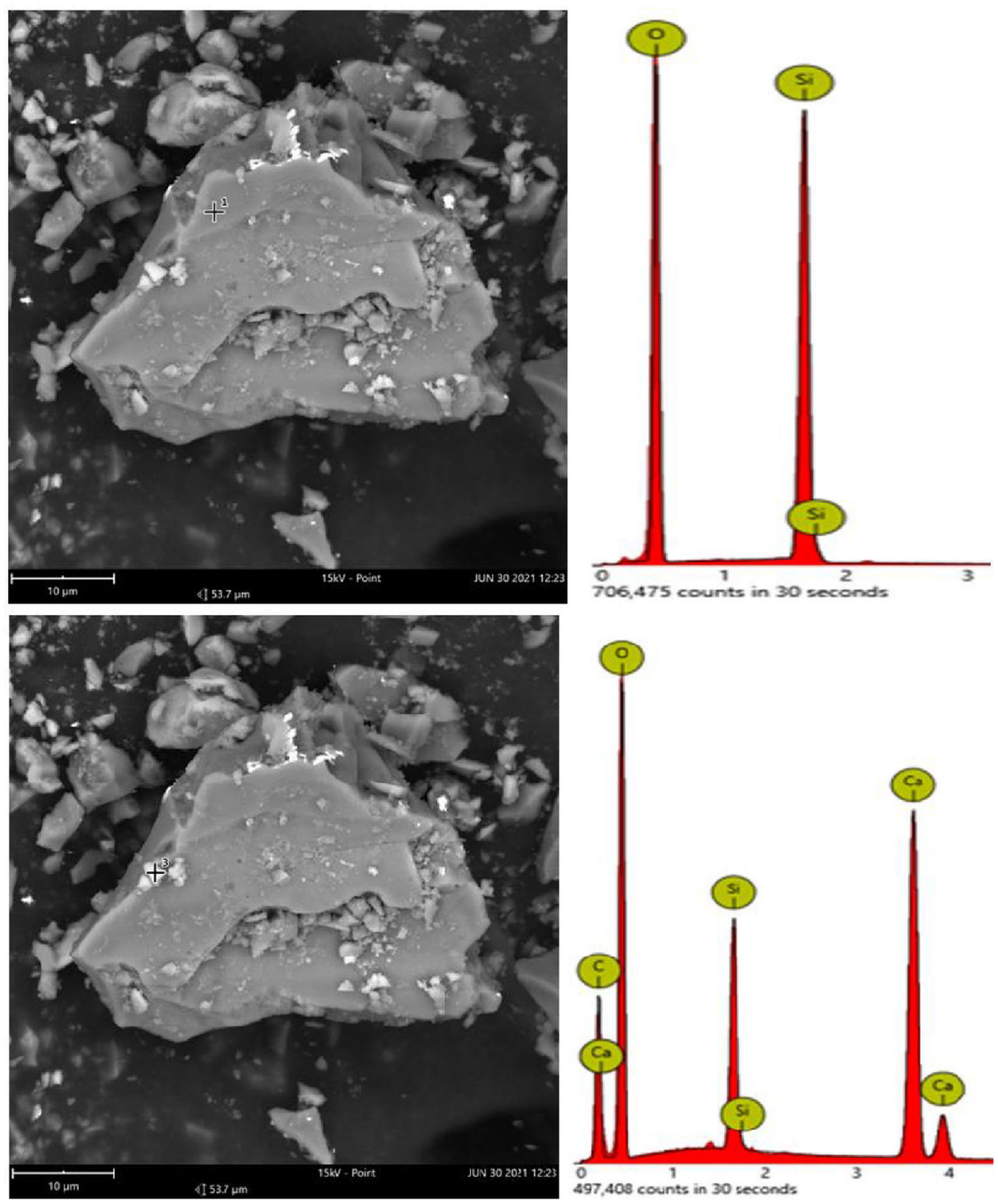

(c)

Fig. 8 (continued)

to use on site for large infrastructure works from a cost/practicality point of view, unless it can be produced at an industrial scale from waste streams (see [17, 18]).

$\mathrm{KOH}$ combined with $\mathrm{Na}_{2} \mathrm{SiO}_{3}$ to treat silt showed potential for the development of very high strengths but such strengths may not be necessary for common applications. In a circular economy context, $\mathrm{KOH}$ can be obtained from $\mathrm{K}_{2} \mathrm{CO}_{3}$ using slaked lime; $\mathrm{K}_{2} \mathrm{CO}_{3}$ itself can be produced by incineration of plant/food waste at less than half the temperatures used for cement production. However, the use of slaked lime to produce $\mathrm{KOH}$ directly from $\mathrm{K}_{2} \mathrm{CO}_{3}$ could 

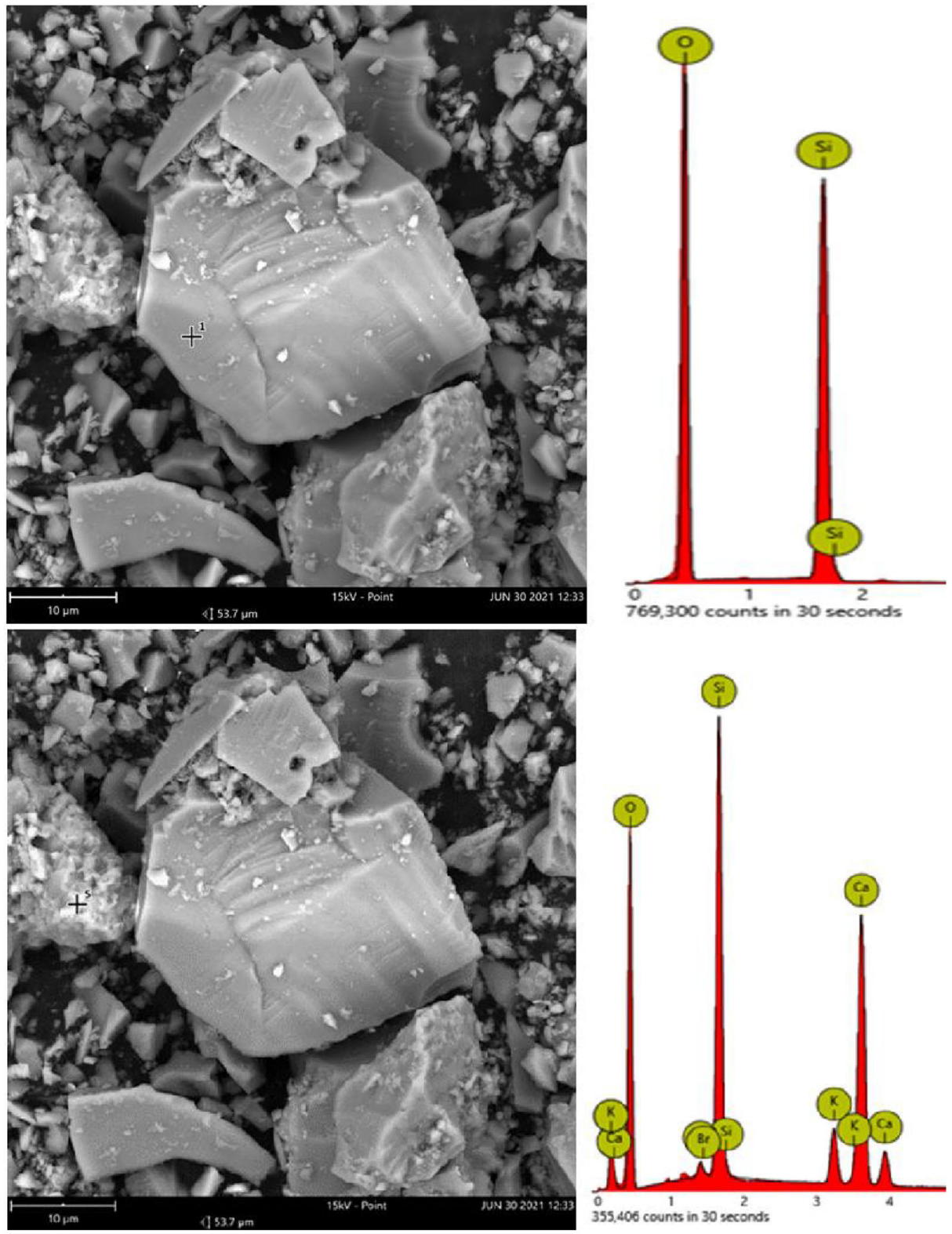

(d)

Fig. 8 (continued)

potentially increase the environmental impact. This could be mitigated by using lime from waste sources, for instance carbide lime [54] or eggshells [55].

Using carbonates on their own gave lower strength increases but these can be sufficient depending on the application. Carbonates could have the advantage of lower alkalinity in the soil compared to hydroxides, which is of practical importance for in situ applications, due to health and 

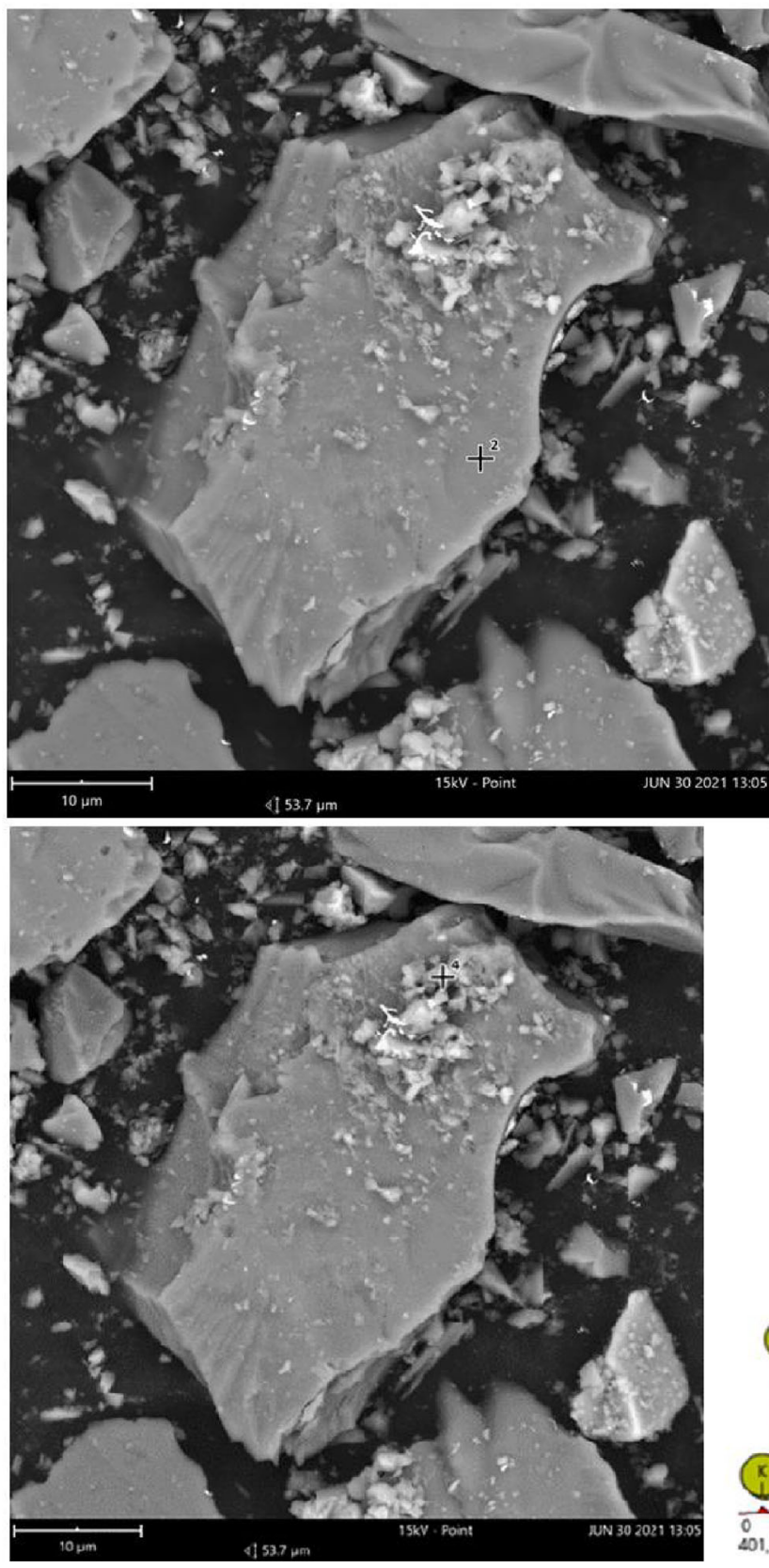

(e)

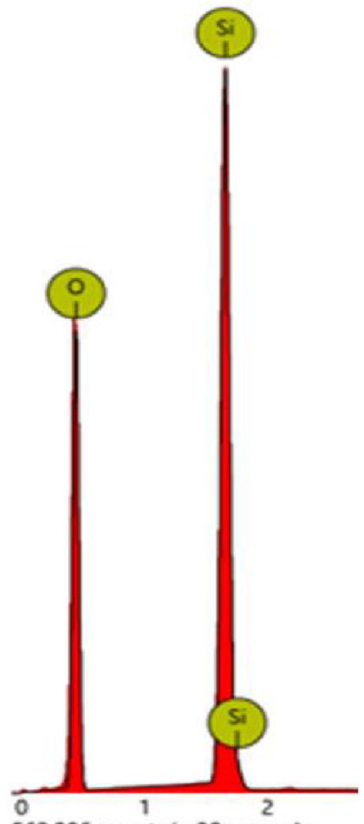

562,906 counts in 30 seconds

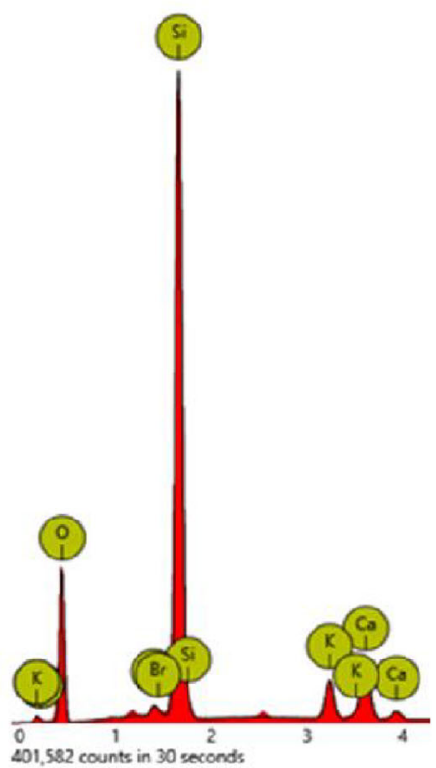

Fig. 8 (continued)

safety of staff and environmental impact reasons. Combining carbonates with $\mathrm{KOH}$ and PSA was shown to enhance their performance. Therefore, carbonates will not be excluded from further study; further research will focus on enhancing their performance through mix optimisation. Moreover, $\mathrm{K}_{2} \mathrm{CO}_{3}$ was shown to be effective in reducing the swelling of the expansive soil. The good 
performance of the potassium-based stabilisers (including $\mathrm{KOH}$ ) with the expansive clay soil in terms of volumetric strain reduction can be due to cation exchange; this could be sufficient for engineering applications where the main problem is to counteract effects of expansive soils on lightweight structures and not strength gain. However, if strength gain is the engineering target, $\mathrm{KOH}$ and in particular $\mathrm{K}_{2} \mathrm{CO}_{3}$, showed a decay in strength when subjected to wetting-drying cycles or when subjected to water curing after 7 days of constant moisture curing. For AAC concrete, exposure in water through water curing has often been reported to result in lower strength gain compared to other curing methods $[34,36,48]$; this was attributed to dilution linked to reduced $\mathrm{pH}$, and the leaching of the activator $[48,56]$. For the AAC systems studied here the exposure of the treated soil in water had perhaps similar effects, although most AAC treated samples were found to have $\mathrm{pH}>10$ (the detailed $\mathrm{pH}$ results were not shown here for brevity). However, unlike precast concrete, where other curing methods could be a better option, for ground improvement applications, regardless of the implementation and curing method, ingress of water in the treated soil can happen at any stage of the treatment. Therefore, ensuring alkali activator systems are durable in the presence of water is of essence and merits further research.

The results were also shown to be very sensitive to the composition of the binder mix. Higher molarities or concentrations of activators did not necessarily lead to higher strengths and in fact using too high a concentration of alkaline activator could lead to a reduction in strength, which has been attributed to premature coagulation due to potentially faster dissolution of precursors in the mixture [48]. Case-by-case optimisation of the mixes appears therefore to be required for a successful engineering design and to minimise activator costs.

\section{Conclusions}

AAC are increasingly gaining interest worldwide as potentially more sustainable alternatives to Portland cement, and particularly suitable for incorporating a large variety of waste materials in the mix composition. Whilst a large number of AAC systems have been used for concrete structures, there is a paucity of knowledge on the use of such cements for soil stabilisation. This feasibility study thus tested a wide number of different AAC systems for soil stabilisation and assessed comparatively their performance. In the context of sustainability and circular economy, the composition of the tested AAC systems comprised industrial by-products, waste materials, or commercially supplied materials that can however be also retrieved from waste or are cheap. The results were encouraging, as all studied AAC mixes improved the UCS and stiffness and reduced the swelling tendency of the studied soils. The highest strengths and stiffness were achieved for $\mathrm{AAC}$ with $\mathrm{KOH}$ and $\mathrm{Ca}(\mathrm{OH})_{2}$ from PSA, which showed comparable strength gains when used in silt, whilst PSA outperformed $\mathrm{KOH}$ in terms of clay mix strengths; PSA mixes showed the best durability to wetting and drying cycles according to preliminary findings. Carbonates and $\mathrm{Na}_{2} \mathrm{SiO}_{3}$ used on their own gave lower strength increases; these increases may however be sufficient depending on the application. Combining these with $\mathrm{KOH}$ and PSA enhanced their performance. Therefore, at this stage these binder components will not be excluded from further studies, towards possible improvement of their performance based on modified mix design. Recommendations for future research thus include further optimisation of the composition of the activator mix, which would be a key for enhanced performance, as the results were sensitive to variations in the binder composition, as well as a comprehensive durability property testing, supported by extensive material analysis (chemical, mineralogical and microstructural) to interpret the mechanical testing findings and elucidate the complex mechanisms involved. 
Code Availability Not applicable

Author Contribution M. Mavroulidou: Conceptualization, Methodology, Supervision, Data analysis, Visualization, Writing — original draft, Writing - review \& editing. C Gray: Experimental methodology and investigation, Data curation (geotechnical soil testing). M.J. Gunn: Conceptualization, Writing-review \& editing. L. Pantoja-Muñoz: Experimental methodology and investigation, Data curation (material analysis).

Funding N/A. The authors carried out the research using their respective university resources.

\section{Declarations}

Parts of the data were originally presented at the 6th International Symposium on Green Chemistry, Sustainable Development and Circular Economy, September 20-23, 2020, Thessaloniki, Greece.

Consent for Publication The authors give consent for the manuscript to be published.

Conflict of Interest The authors declare no competing interests.

Data Transparency The authors' team declare that all data and materials comply with field standards.

Open Access This article is licensed under a Creative Commons Attribution 4.0 International License, which permits use, sharing, adaptation, distribution and reproduction in any medium or format, as long as you give appropriate credit to the original author(s) and the source, provide a link to the Creative Commons licence, and indicate if changes were made. The images or other third party material in this article are included in the article's Creative Commons licence, unless indicated otherwise in a credit line to the material. If material is not included in the article's Creative Commons licence and your intended use is not permitted by statutory regulation or exceeds the permitted use, you will need to obtain permission directly from the copyright holder. To view a copy of this licence, visit http://creativecommons.org/licenses/by/4.0/.

\section{References}

1. Du Y-J, Yu B-W, Liu K, Jiang N-J, Liu MD (2016) Physical, Hydraulic, and Mechanical Properties of Clayey Soil Stabilized by Light-weight Alkali-Activated Slag Geopolymer. J Mater Civ Eng 29:04016217. https://doi.org/10.1061/(ASCE)MT.1943-5533.0001743

2. Safdar MU, Mavroulidou M, Gunn MJ, Purchase D, Gray C, Payne I, Garelick J (2021) Towards the development of sustainable ground improvement techniques - biocementation study of an organic soil. Circ Econ Sust. https://doi.org/10.1007/s43615-021-00071-8

3. Provis J1 (2018) Alkali-activated materials. Cem Concr Res 114:40-48

4. Yang K-H, Song J-K, Song K-I (2013) Assessment of CO2 reduction of alkali-activated concrete. J Clean Prod 39:265-272

5. Phetchuay C, Horpibulsuk S, Arulrajah A, Suksiripattanapong C, Udomchai A (2016) Strength development in soft marine clay stabilized by fly ash and calcium carbide residue based geopolymer. Appl Clay Sci 127-128:134-142

6. Provis JL (2014) Introduction and scope. In: Provis JL, van Deventer JSJ (eds) Alkali-activated materials: state-of-the-art report, RILEM TC 224-AAM. Dordrecht, Springer, 1-11

7. Pacheco-Torgal F, Castro-Gomez J, Jalali S (2008) Properties of tungsten mine waste geopolymeric binder. Constr Build Mater 22(6):1201-1211

8. Reig L, Tashima MM, Soriano L, Borrachero M, Monzó JV, Payá J (2013) Alkaline activation of ceramic waste materials. Waste Biomass Valorization 4:729-736

9. Komnitsas K, Zaharaki D, Vlachou A, Bartzas G, Galetakis M (2015) Effect of synthesis parameters on the quality of construction and demolition wastes (CDW) geopolymers. Adv Powder Technol 26:368-376 
10. Robayo-Salazar RA, Rivera JF, Mejía de Gutiérrez R (2017) Alkali-activated building materials made with recycled construction and demolition wastes. Constr Build Mater 149:130-138

11. Sturm P, Gluth JGJ, Brouwers HJH, Kühne H.-C. (2016) Synthesizing one-part geopolymers from rice husk ash Construction and Building Materials 124: 961-966.

12. Sore S.O., Messan A., Prud'homme E, Escadeillas, G., Tsobnang F. (2016) Synthesis and characterization of geopolymer binders based on local materials from Burkina Faso - Metakaolin and rice husk ash, 124: 301-311.

13. Ferone C, Colangelo F, Messina F, Santoro L, Cioffi R (2013) Recycling of pre-washed municipal solid waste incinerator fly ash in the manufacturing of low temperature setting geopolymer materials. Materials 6 : 3420-3437

14. Ye N, Chen Y, Chang J et al (2016) Co-disposal of MSWI fly ash and Bayer red mud using a one-part geopolymeric system. J Hazard Mater 318:70-78

15. Geng JJ, Zhou M, Li Y, Chen Y, Han Y, Wan S, Zhou X, Hou H (2017) Comparison of red mud and coal gangue blended geopolymers synthesized through thermal activation and mechanical grinding preactivation. Constr Build Mater 153:185-192

16. Pourakbar S, Huat BBK, Asadi A, Fasihnikoutalab MH (2016) Model Study of Alkali-Activated Waste Binder for Soil Stabilization. Int. J of Geosynth and Ground Eng 2:35

17. Jamieson E, McLellan B, van Riessen A, Nikraz H (2015) Comparison of embodied energies of Ordinary Portland Cement with Bayer-derived geopolymer products. J Clean Prod 99:112-118

18. Tchakouté HK, Rüscher C, Kong H, S. Kamseu E., Leonelli C. (2016) Geopolymer binders from metakaolin using sodium waterglass from waste glass and rice husk ash as alternative activators: A comparative study. Constr Build Mater 114:276-289

19. Handayani L, Aprilia S, Abdullah et al Synthesis of Sodium Silicate from Rice Husk Ash as an Activator to Produce Epoxy-Geopolymer Cement. J Phys Conf Ser 2021, 1845:012072

20. Dumée LF (2021) Circular Materials and Circular Design—Review on Challenges Towards Sustainable Manufacturing and Recycling. Circular Economy and Sustainability. https://doi.org/10.1007/s43615-02100085-2

21. Cristelo N, Glendinning S, Pinto AT (2011) Deep soft soil improvement by alkaline activation. Proceedings of the ICE-Ground Improvement 164:73-82

22. Cristelo N, Glendinning S, Fernandes L, Pinto AT (2012) Effect of calcium content on soil stabilisation with alkaline activation. Constr Build Mater 29:167-174

23. Cristelo N, Glendinning S, Fernandes L, Pinto AT (2013) Effects of alkaline-activated fl y ash and Portland cement on soft soil stabilisation. Acta Geotech 8:395-405

24. Sargent, P. (2015) Development of a Low Carbon Geopolymer for High-Speed Rail Proceedings of the 24th European Young Geotechnical Engineers Conference (EYGEC), Durham, UK (Eds.Osman, A.S. \& Toll, D.G.) ISBN 978-0-9933836-01

25. Zhang M, Guo H, El-Korchi T, Zhang G, Tao M (2013) Experimental feasibility study of geopolymer as the next-generation soil stabilizer. Constr Build Mater 47:1468-1478

26. Coudert E, Paris M, Deneele D, Russo G, Tarantino A (2019) Use of alkali activated high-calcium fly ash binder for kaolin clay soil stabilisation: Physicochemical evolution. Constr Build Mater 201:539-552

27. Vitale E, Russo G, Dell'Agli G, Ferone C, Bartolomeo C (2017) Mechanical Behaviour of Soil Improved by Alkali Activated Binders. Environments 4:80. https://doi.org/10.3390/environments4040080

28. Vitale E, Russo G, Daneele D (2019) Multi-scale analysis on soil improved by alkali activated binders, ISGlasgow 2019. E3S Web of Conferences 92(2019):11003. https://doi.org/10.1051/e3sconf/20199211003

29. Syed M, GuhaRay A, Kar A (2020) Stabilization of Expansive Clayey Soil with Alkali Activated Binders. Geotech Geol Eng. https://doi.org/10.1007/s10706-020-01461-9

30. Mavroulidou M., Gray C., Gunn MJ, Mbey P., Nangyal H. (2019) A laboratory study of innovative cementing agents, as alternatives to conventional soil stabilisers, XVII ECSMGE European Conference on Soil Mechanics and Geotechnical Engineering, Reykjavik, Iceland 1st- 6th September 2019

31. Mavroulidou M., Gray C., Gunn MJ (2020) Alkali-activated cements for ground improvement, 6th International Symposium on Green Chemistry, Sustainable Development and Circular Economy (Greenchem6), Thessaloniki, 20-23 September 2020 ISBN:978-618-5494-13-1

32. Garcia-Lodeiro I, Palomo A, Fernandez-Jimenez A (2015) An Overview of the Chemistry of AlkaliActivated Cement Based Binders. In: Handbook of Alkali-activated Cements, Mortars and Concretes. Woodhead Publishing ser civ struct eng. Number 54:19-47

33. Provis J1, Palomo A, Shi C (2015) Advances in understanding alkali-activated materials. Cem Concr Res 78A: $110-125$

34. Mavroulidou M, Martynková R (2018) A study of alkali-activated concrete mixes with ground granulated blast furnace slag. Global Nest Journal 20:216-225. https://oi.org/10.30955/gnj.002370

35. Mavroulidou M (2018) Use of paper sludge ash as a calcium-based stabiliser for clay soils. Waste Manag Res 36:1066-1072 
36. Martynková R, Mavroulidou M (2015) Properties of alkali-activated concrete based on industrial wastes or by-products, $14^{\text {th }}$ Int. Conf. on Environmental Science and Technology, Rhodes, Greece, 3-5 September 2015 http://cest2015.gnest.org/papers/cest2015_00439_oral_paper.pdf [Accessed 08/09/2017]

37. Bernal S, Ball R, Hussein O, et al. (2014) Paper sludge ash as a precursor for production of alkali-activated materials. In: 2nd international conference on advances in chemically activated materials, Changsha, China, 1-3 June 2014.

38. Spathi C (2015) Novel applications for paper sludge ash. PhD thesis, Imperial College, London

39. British Standards Institution (BSI) (1990) BS 1377-2:1990 (Incorporating Amendment No. 1): Methods of test for Soils for civil engineering purposes - Part 2: Classification tests, London: BSI.

40. Wang S, Scrivener KL, Pratt PL (1993) Factors Affecting the Strength of Alkali-Activated Slag. Cem Concr Res 24(6):1033-1043

41. Chuah S, Duan WH, Pan Z, Hunter E, Korayem AH, Zhao XL, Collins F, Sanjayan JG (2016) The properties of fly ash based geopolymer mortars made with dune sand. Mater Des 92:571-578

42. Bernal SA, Provis JL, Myers RJ, San Nicolas R, Van Deventer JSJ (2015) Role of carbonates in the chemical evolution of sodium carbonate-activated slag binders. Mater Struct 48(3):517-529

43. Mavroulidou M, Shah S (2021) Alkali-activated slag concrete with paper industry waste. Waste Manag Res 39(3):466-472

44. Mengasini L, Mavroulidou M, Gunn MJ (2021) Alkali-activated concrete mixes with ground granulated blast furnace slag and paper sludge ash in seawater environments. Sustain Chem Pharm 20(2):100380. https://doi.org/10.1016/j.scp.2021.100380

45. Mavroulidou M., Garelick J., Gray C., Gunn MJ, Youssef A., Hassan S. (2019) A study on the use of paper recycling waste streams for geotechnical applications, XVII ECSMGE European Conference on Soil Mechanics and Geotechnical Engineering, Reykjavik, Iceland $1^{\text {st }}-6^{\text {th }}$ September 2019

46. Tashima MM, Reig L, Santini MA Jr, Moraes JCB, Akasaki JL, Payá J, Borrachero MV, Soriano L (2017) Compressive Strength and Microstructure of Alkali-Activated Blast Furnace Slag/Sewage Sludge Ash (GGBS/SSA) Blends Cured at Room Temperature. Waste Biomass Valorisation 8:1441-1451

47. Newbury DE (2007) Mistakes encountered during automatic peak identification in low beam energy X-Ray microanalysis. Scanning 29:137-151

48. Nodehi M, Taghvaee VM (2021) Alkali-Activated Materials and Geopolymer: a Review of Common Precursors and Activators Addressing Circular Economy. Circ Econ Sust. https://doi.org/10.1007/s43615021-00029-w

49. Kryvenko P, Rudenko, Konstantynovskyi O., Boiko O. (2021) Restriction of $\mathrm{Cl}^{-}$and $\mathrm{SO}_{4}{ }^{2-}$ Ions Transport in Alkali Activated Slag Cement Concrete in Seawater Institute Of Physics Conference Series: Materials Science and Engineering, 1164: 012066 (online) https://iopscience.iop.org/article/10.1088/1757-899X/ $1164 / 1 / 012066$

50. Wild S, Kinuthia JM, Jones GI, Higgins DD (1999) Suppression of swelling associated with ettringite formation in lime stabilized sulphate bearing clay soils by partial substitution of lime with ground granulated blast furnace slag. Eng Geol 51(4):257-277

51. Mavroulidou M, Awoliyi S (2018) A study on the potential use of paper sludge ash in concrete with glass aggregate. Waste Manag Res 36(11):1061-1065

52. Mavroulidou M., Ziniatis A., Gray C, et al (2017) Alternative calcium-based chemical stabilisers for ground improvement: Paper Sludge Ash treatment of London Clay, $15^{\text {th }}$ International Conference on Environmental Science and Technology Rhodes, Greece, 31 August to 2 September 2017

53. Mavroulidou M, Gray C, Gumbochuma F and Gunn MJ (2020) A comparative assessment of chemical stabilisers including waste materials, for the treatment of swelling-shrinking soils, $4^{\text {th }}$ European Conference on Unsaturated Soils (E-UNSAT2020), Lisbon 21-24 October 2020, E3S Web of Conferences 195, 03028 (2020 https://doi.org/10.1051/e3sconf/202019503028

54. Chukwudebelu JA, Igwe CC, Taiwo OE, Tojola OB (2013) Recovery of pure slaked lime from carbide sludge: Case study of Lagos state, Nigeria. Afr J Environ Sci Technol 7(6):490-495

55. Pedavoah M-M, Badu M, Boadi NO, Awudza JAM (2018) Green Bio-Based CaO from Guinea Fowl Eggshells. Green Sustain Chem 8:208-219

56. Lizcano M, Gonzalez A, Basu S, Lozano K, Radovic M (2012) Effects of water content and chemical composition on structural properties of alkaline activated metakaolin-based geopolymers. J Am Ceram Soc 95(7):2169-2177 


\section{Affiliations}

M. Mavroulidou ${ }^{1}$ - C. Gray ${ }^{2}$ • M. J. Gunn ${ }^{1} \cdot$ L. Pantoja-Muñoz ${ }^{3}$

1 Division of Civil and Building Services Engineering, BEA, London South Bank University, 103 Borough Road, London SE1 0AA, UK

2 London South Bank University, London, UK

3 Faculty of Science and Technology, Middlesex University, London, UK 